\title{
Minimum-Fuel Ascent of a Hypersonic Vehicle Using Surrogate Optimization
}

\author{
Derek J. Dalle,,- Sean M. Torrez, $\stackrel{\perp}{-}$ and James F. Driscoll \\ University of Michigan, Ann Arbor, Michigan 48109 \\ Michael A. Bolender $\stackrel{\S}{-}$ \\ U.S. Air Force Research Laboratory, Wright-Patterson Air Force Base, Ohio 45433 \\ and \\ Kevin G. BowcuttI \\ The Boeing Company, Huntington Beach, California 92647
}

DOI: $10.2514 / 1 . C 032617$

\begin{abstract}
A general strategy is identified to compute the minimum fuel required for the ascent of a generic hypersonic vehicle that is propelled by a dual-mode ramjet-scramjet engine with hydrogen fuel. The study addresses the ascent of an accelerator vehicle rather than a high-speed cruiser. Two general types of ascent trajectories are considered: acceleration within scramjet mode, and acceleration across the ramjet-scramjet transition boundary maximum acceleration and maximum dynamic pressure (lowest allowed altitude) were shown to be near optimum for scramjetmode trajectories, but optimized trajectories were found to be more complex when both modes are considered. The first-principles model used in this paper computes the combustion efficiency using finite-rate chemistry and a fuel-air mixing model. It also computes the inlet efficiency with a shock wave interaction code, and thus avoids empirical formulas for efficiency that were used in previous models.
\end{abstract}

\section{Nomenclature}

$A$

A

$a$

$B$

$d$

$\boldsymbol{F}$

$f$

$f$

I

I

$L$

$M$

M

$m$

$N$

$\hat{\boldsymbol{n}}$

$P$

$Q$

$q$

$r_{s}$

$t, \tau$

$u$

u $=$

$V \quad=$

$x, y, z=$

acceleration

diameter

specific force vector

$=$ geodetic altitude

$=$ Mach number

$=$ mass

$=$ unit normal vector

$=$ roll rate

$=$ pitch rate

$=$ dynamic pressure

= yaw rate

$=$ stoichiometric ratio

time

flow velocity

spatial coordinates empirical mixing constant

state linearization matrix

control variable linearization matrix

generic vector function

$=$ moment or product of inertia

$=$ length or geodetic latitude

$=$ specific moment vector

$=$ number of injection ports per meter

vector of control variables or velocities

magnitude of vehicle velocity
Received 10 September 2013; revision received 4 January 2014; accepted for publication 5 January 2014; published online 25 April 2014. This material is declared a work of the U.S. Government and is not subject to copyright protection in the United States. Copies of this paper may be made for personal or internal use, on condition that the copier pay the $\$ 10.00$ per-copy fee to the Copyright Clearance Center, Inc., 222 Rosewood Drive, Danvers, MA 01923; include the code $1542-3868 / 14$ and $\$ 10.00$ in correspondence with the CCC.

*Postdoctoral Research Fellow, Department of Aerospace Engineering; dalle@umich.edu. Member AIAA.

†Alumnus, Department of Aerospace Engineering; smtorrez@umich.edu. Member AIAA.

Frofessor, Department of Aerospace Engineering; jamesfd@umich.edu. Fellow AIAA.

${ }^{\S}$ Senior Aerospace Engineer. Associate Fellow AIAA.

"Senior Technical Fellow \& Chief Scientist of Hypersonics, Boeing Research \& Technology, 5301 Bolsa Ave./H45N-E406. Fellow AIAA.

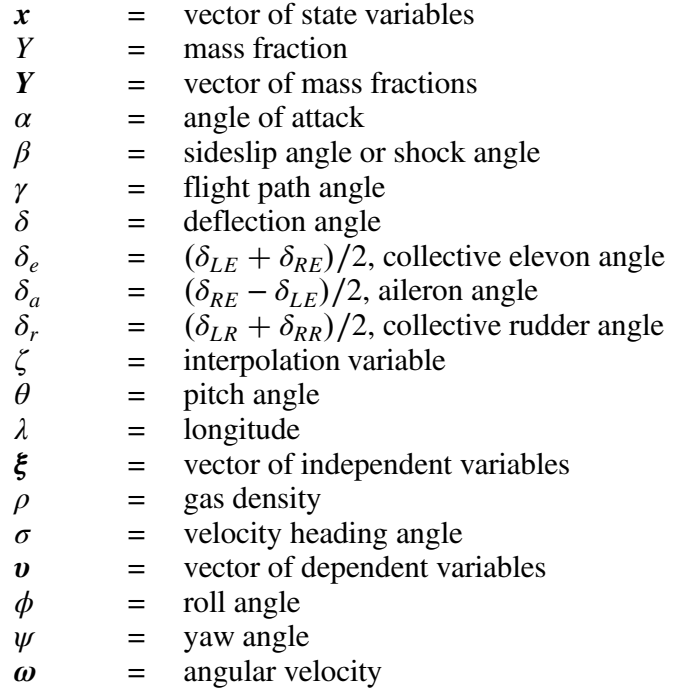

Subscripts and superscripts

$\begin{array}{lll}\infty & = & \text { freestream value } \\ A & = & \text { core flow } \\ b & = & \text { body frame } \\ \mathrm{cg} & = & \text { center of gravity } \\ f & = & \text { fuel or fuel injection jet } \\ i & = & \text { trajectory segment index } \\ n & = & \text { navigation frame } \\ \infty & = & \text { freestream value }\end{array}$

\section{Introduction}

$\mathbf{T}$ HERE have been several previous studies of the optimization of a trajectory for a hypersonic vehicle that is propelled by a scramjet engine [1-9]; however, there are a number of research issues that still need to be addressed. Instead of assuming empirical relations for the combustion efficiency and inlet efficiencies, these quantities should be computed using a first-principles model. The tradeoffs associated with the governing parameters should be explored systematically. Trajectory optimization during conceptual design is 
performed using a point mass model of the vehicle, so the vehicle should be trimmed at each time step along its ascent. For example, the engine fuel-air equivalence ratio (ER) is not free to be selected a priori; it is a dependent variable that must take on a value that provides just enough thrust to balance the drag, gravity, and acceleration terms. The present work addresses all of these research issues.

The specific goal of this work is to determine the optimum vehicle acceleration $a$ and altitude $h$ history that minimizes the total amount of fuel required to accelerate a vehicle from one Mach number to another. The vehicle considered in this work is an accelerator that uses $\mathrm{H}_{2}$ fuel. The analysis assumes that the vehicle is able to reach or be propelled to a certain initial Mach number at which ramjet-mode flight is possible and flight at lower Mach numbers is not analyzed.

In this work, we define acceleration and dynamic pressure to be the decision variables that can be selected by the designer. All other variables, such as fuel-air equivalence ratio and angle of attack $\alpha$ are dependent variables that are determined by the trim code. Two ranges of Mach numbers are considered. The first range of Mach numbers is from 7 to 13; this allows the vehicle to remain in scram mode throughout the trajectory, which simplifies the optimization. The second class of trajectories is from Mach 4.5 to Mach 7, which includes a transition from ramjet (ram) mode to scramjet (scram) mode. The efficiencies of the inlet, combustor, and nozzle are computed using a first-principles model rather than using empirical relations.

Previously, the optimization of the ascent of a hypersonic vehicle was performed by Calise et al. [2], Corban et al. [3], Powell et al. [4], Olds and Budianto [5], McGinnis [6], and Lu [7,8]. Their vehicle models use empirical or algebraic formulas for combustion and inlet efficiencies, and they ignored important couplings such as the sensitivity of thrust to angle of attack. They employed some unrealistic assumptions: for example, that lift is proportional to angle of attack. This is not true for many scramjet-powered vehicles because the lift is directly affected by the thrust setting. An increase in thrust raises the pressure in the nozzle, which also increases the lift. This result is apparent from inspection of the nozzle design, and it has been verified experimentally by Robinson et al. [10]. Except for [4]], these previous studies did not account for trim drag.

Most important, most of the previous studies did not directly discuss what the fuel-air equivalence ratio should be for an optimal trajectory. For example, Corban et al. [3] assume that the scramjet engine is operated at an equivalence ratio of unity and use an additional rocket engine for thrust control. Lu [7] discusses equivalence ratio, but the simplistic engine model (assumption of $100 \%$ combustion efficiency for all flight conditions) leads to an equivalence ratio of unity. In real scramjet engines, the efficiency is not $100 \%$, and it decreases as the Mach number increases. The most important contribution of the present work is that it identifies that the engine should be operated rich (equivalence ratio greater than unity). Enough fuel should be injected so that nearly all of the available oxygen is used, and the remaining fuel can be used for film cooling.

There are several interesting tradeoffs that are unique to airbreathing hypersonic engines. For example, it is well known that a rocket wants to maximize its acceleration early in the trajectory in order to reduce the distance that the propellant must be lifted against gravity. With an airbreathing engine, the problem is more complicated. A scramjet-powered vehicle uses lift rather than thrust to counter gravity, and so potential energy is less of a concern. Burning too much fuel may cause thermal choking in the combustor or lead to unstart, and so the maximum acceleration may correspond to equivalence ratios below unity. At higher Mach numbers, combustion efficiency tends to decrease, and equivalence ratios greater than unity may be appropriate.

There are also tradeoffs associated with the dynamic pressure. If a trajectory with a higher dynamic pressure is selected, the vehicle reaches higher speeds at relatively low altitudes. This increases both the static pressure in the combustor and the combustion efficiency. Selecting a larger dynamic pressure is also desirable because it leads to a smaller angle of attack because the lift force and vehicle weight are balanced. For these two reasons, in scram mode, the fuel consumption is usually minimized by selecting the highest dynamic pressure allowed by structural considerations $[\underline{4}, \underline{5}, \underline{7}, \underline{8}]$. In this work, we show that the introduction of ram-to-scram transition into the trajectory leads to more complex results such that lower dynamic pressures may be favorable for portions of the trajectory.

To explore the above tradeoffs, a surrogate-based method was applied to optimize the trajectory of a hypersonic vehicle. Surrogatebased optimization requires that the model be run many times in order to develop a set of response surfaces. For example, one response surface is generated by plotting the trimmed fuel mass flow rate $\dot{m}_{f}$ as a function of acceleration $a$, flight Mach number $M$, and vehicle mass $m$. Curve fitting is used to interpolate between the discrete values on each response surface. Then, the problem is reduced to finding the path along the response surface that minimizes the total fuel consumed.

The propulsion model that was used is called the MASIV [Michigan/U.S. Air Force Research Laboratory (AFRL) scramjet in vehicle] [11-14], and the vehicle code is called MASTrim (Michigan/ AFRL scramjet trim). These two codes are based on the original Bolender-Doman model [15], but with additional complex phenomena such as shock wave interactions, fuel-air mixing, and finite-rate chemistry. At each time step, the model computes the forces on the vehicle and calculates a trimmed flight condition. Reduced-order models such as MASIV are required because highfidelity computational fluid dynamics (CFD) is too computerintensive to create the response surfaces that relate all possible variable combinations required for the trajectory optimization. For example, the response surfaces used for the scram-mode optimization contain 91 trimmed flight conditions (13 Mach numbers and 7 accelerations), and each vehicle trim requires calculating the forces and moments about 15 times (4 to calculate the initial gradient, and about 10 guesses of input variables until trim conditions are satisfied), so the model must be run about 1300 times to create each response surface.

Several related previous studies did not optimize the trajectory but instead optimized the vehicle geometry for a fixed flight condition. These were reported by Bowcutt et al. [16-18] and others [19-23]. Other efforts focused on the development of models of hypersonic vehicles but did not attempt any optimization. These include works by Bolender and Doman [15], Oppenheimer et al. [24], Bolender and Doman [25], Chavez and Schmidt [26], Starkey [27], Frendreis and Cesnik [28], Torrez et al. [12], and Dalle et al. [11,13,29]. Carter et al. [30] analyzed a vehicle undergoing repeated climbing and gliding but

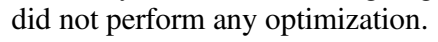

Previous work by the present authors led to the development of the MASTrim code $[11-13,31,32]$, which contains the MASIV engine model. It includes the rotational ellipsoidal-Earth equations of motion and tools for trim and stability analysis. As a whole, MASTrim is a collection of first-principles models that can model such effects as shock interactions, fuel-air mixing, and finite-rate chemistry but can also calculate the forces on a vehicle in about $5 \mathrm{~s}$ using a single processor with a clock speed of approximately 2.6 GHz. The next sections describe the vehicle and the MASTrim code.

\section{Vehicle Model}

The vehicle that was selected for this work is a generic waverider that is called Michigan/AFRL Experimental 1 (MAX-1), and is shown in Figs. 1 and 2 . Although it is not an optimized design, it contains realistic values of the areas for the control surfaces, lifting surface, and engine entrance. The lengths of the inlet panels, isolator, combustor, and nozzle were selected to yield adequate performance so that trim can be achieved for a wide range of flight conditions.

In Fig. 2, the shaded triangles show the surfaces that are analyzed by the engine model, while the remaining surfaces are analyzed by the external aerodynamics model. Standard body-fixed flight mechanics coordinates are used for the vehicle: the $x$ axis points forward, the $y$ axis points to the right of the vehicle, and the $z$ axis points downward. The origin is at the center of the vehicle leading edge. 


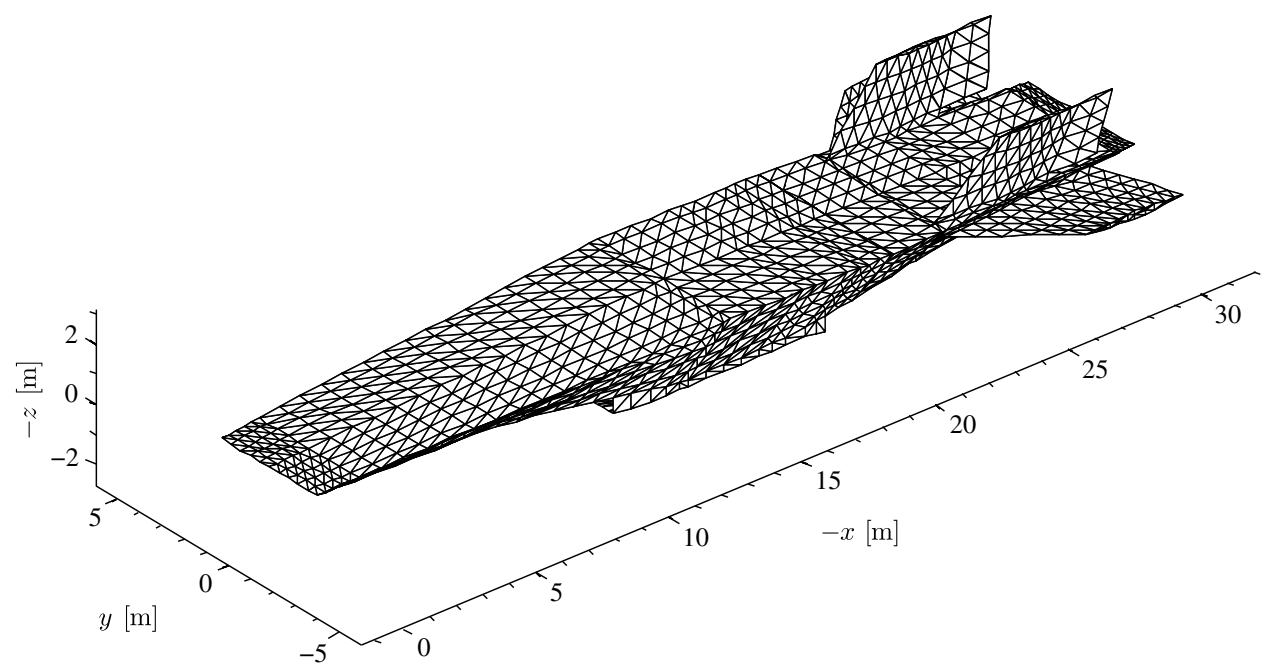

Fig. 1 Upper view of the MAX-1 vehicle.

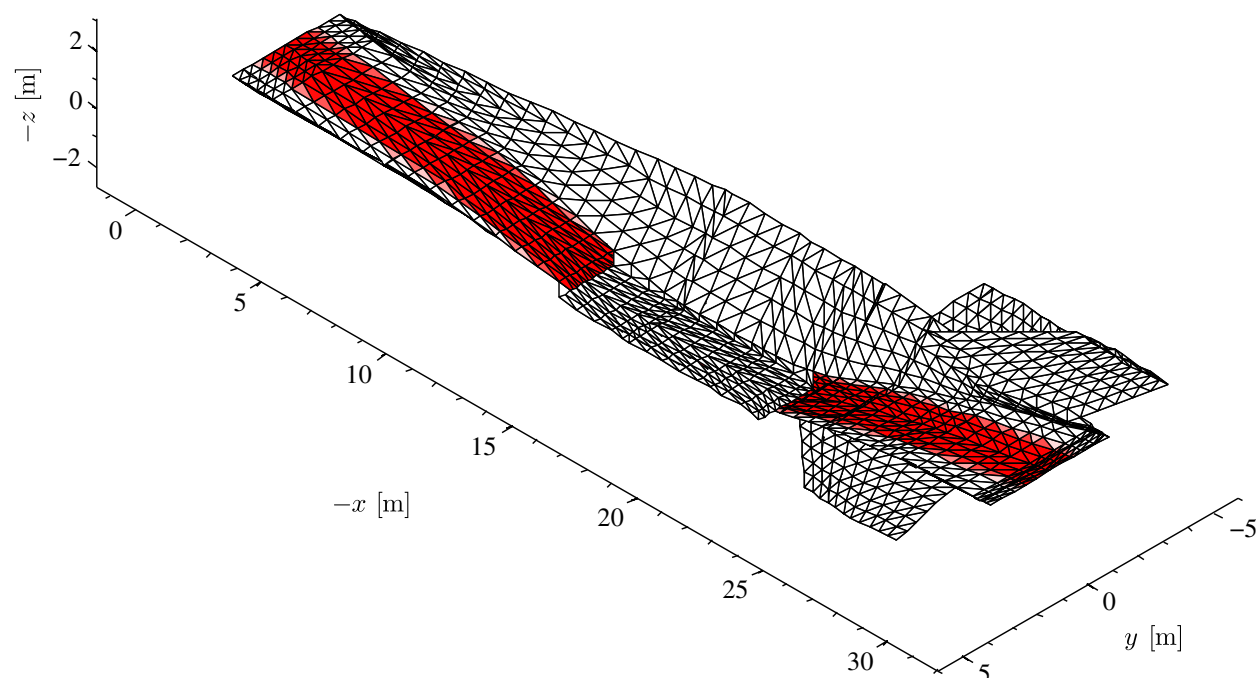

Fig. 2 View of the MAX-1 vehicle from below with propulsive surfaces shaded.

The MASTrim vehicle model is split into several sections that interact with each other. The engine model, which is called MASIV, is split into inlet, isolator, combustor, and nozzle models. The rest of the MASTrim model is a simple exterior aerodynamics model and a program to compute the equations of motion. Figure $\underline{3}$ shows how information is passed among these components with distinct appearances for inputs (white boxes with square corners), vehicle submodels (gray boxes), and auxiliary models (dark boxes with white text). In Fig. 3, solid lines represent information directly from the inputs, dashed lines show forces and moments, and dotted lines represent thermodynamic state information.

The MASTrim model is capable of constructing and analyzing a range of vehicles that are based on a set of about 50 design parameters. The vehicle shown in Figs. 1 and 2 has a length of $28.5 \mathrm{~m}$ and is designed to operate at Mach numbers ranging from Mach 7 to Mach 11. It is referred to as the MAX-1A vehicle throughout the rest of the work, and the horizontal width of the engine is $2.14 \mathrm{~m}$, while the nose width is $2.14 \mathrm{~m}$. The maximum vehicle width is $6.00 \mathrm{~m}$. The maximum vertical width of the vehicle (not counting the tails) is $2.79 \mathrm{~m}$. The fuel is hydrogen for all simulations.

An alternate vehicle (called MAX-1B in subsequent references) has mostly the same parameters (length, width, etc.) but is designed to operate at Mach numbers between 5 and 7. The MAX-1B design provides better performance for investigating trajectories, which is the subject of Sec. IV.D.

The vehicle design is not the result of a formal multidisciplinary design optimization, but each component has been selected according to certain design principles. For example, the changing shock positions that result from changing Mach number and angle of attack have a significant impact on the inlet performance, and the design has been chosen explicitly to have acceptable performance for a range of Mach numbers and angles of attack [33,34].

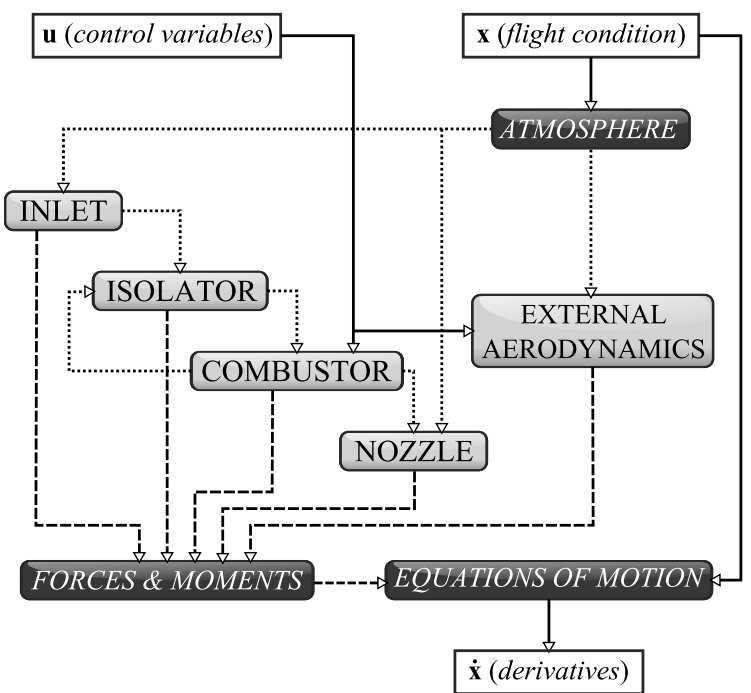

Fig. 3 Overview of information flow within the MASTrim program. 


\section{A. Inlet and Exhaust Nozzle Models}

The inlet is a two-dimensional design and is modeled using a fully two-dimensional analysis called SAMURI (supersonic aerodynamic method using Riemann interactions). In [11], we compared the static pressure profile and stagnation pressure loss against two-dimensional CFD (computational fluid dynamics) and a three-dimensional experiment, and we found the results to agree to within $6 \%$ consistently. The same model is also applied to the two-dimensional scramjet nozzle design, and other work has showed SAMURI to predict local surface pressure to within $6 \%$ with those of a linear plug nozzle experiment and two-dimensional CFD [13].

The SAMURI model tracks two-dimensional shock and expansion waves. The properties of each wave can be calculated using simple oblique shock analysis [35] or a discretized form of Prandtl-Meyer expansion theory [13]. Leading edges and other vertices of the inlet geometry each introduce at least one wave, and each wave can interact with the surface of the inlet or other waves. When two or more waves interact, the result is a Riemann problem as described in [13].

Figure 4 shows a contour plot of the temperature solution for the vehicle in Figs. 1 and 2. The inlet shown here is designed for operation at Mach numbers between 7 and 11 and angles of attack between -0.5 and $+1 \mathrm{deg}$. The angles of the external ramps are 4.7 and $11.9 \mathrm{deg}$. At Mach 8, this means that there is a substantial amount

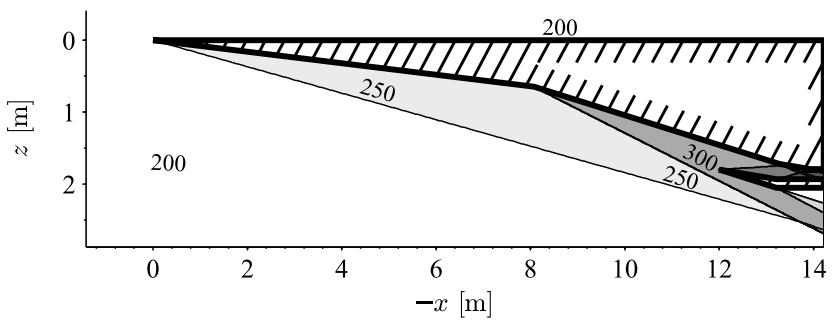

a) Inlet

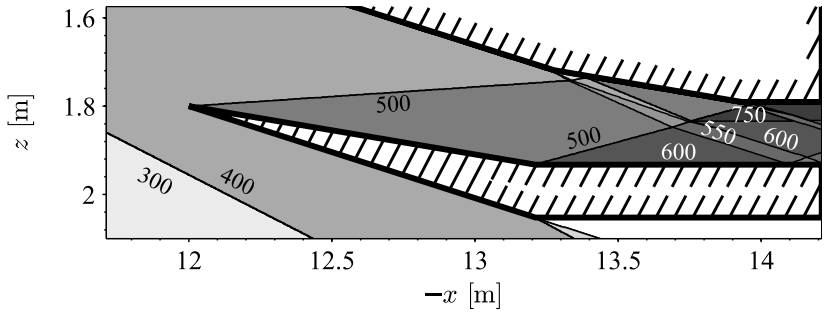

b) Inlet cowl region

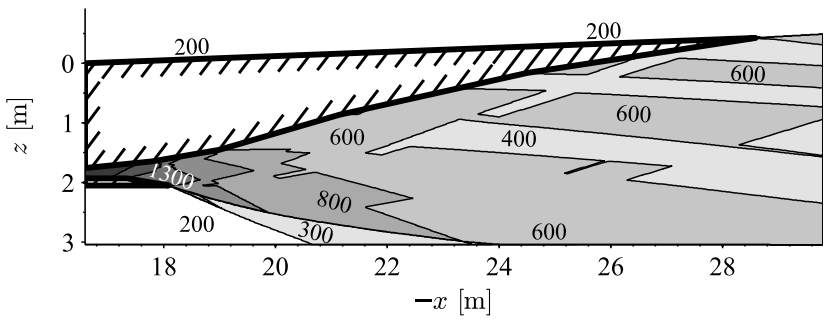

c) Nozzle

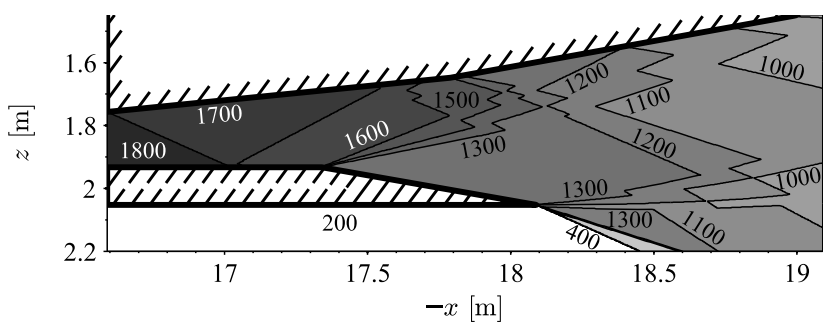

d) Nozzle cowl region

Fig. 4 Contours of temperature in kelvins at a trimmed Mach 8 flight condition. of spillage, which can be seen from the fact that the shock in the lower left corner of Fig. 4b is some distance away from the cowl leading edge. Furthermore, the shock that originates at the cowl leading edge hits the inlet body downstream of the body vertex that is often called a "shoulder." At the highest design Mach number, 11, this shock would hit the body just upstream of the next body vertex downstream (or second shoulder).

\section{B. Combustor/Isolator Mode}

The combustor model is a quasi-one-dimensional model, but fuelair mixing and heat release are modeled as three-dimensional processes [12]. That is, the fuel is injected from the wall as a threedimensional jet in a crossflow, and the local fuel mixture fraction profiles are determined from measured scaling relations. At each $(x, y, z)$ location, the fuel mixture fraction is converted into a chemical reaction rate using turbulent mixing and combustion lookup table. The reaction rates are integrated into the one-dimensional fluid flow conservation equations, which are ordinary differential equations for the thermodynamic states $\rho, p, T$, and $u$, and the mass fractions $\boldsymbol{Y}$. The reaction rates $\dot{\boldsymbol{Y}}$ are a function of all three spatial coordinates given by

$$
\frac{\mathrm{d} \boldsymbol{Y}}{\mathrm{d} x}=\frac{1}{u} \dot{\boldsymbol{Y}}(x)=\frac{1}{u} \iint \dot{\boldsymbol{Y}}(x, y, z) \mathrm{d} y \mathrm{~d} z
$$

More details on both the thermodynamic equations and the finite-rate chemistry model can be found in [12].

When the vehicle is operating in full scram mode, the isolator does not establish a shock train, and the solution steps directly from inlet to isolator to combustor to nozzle without any feedback from the downstream components. However, when the vehicle goes into ram mode, the isolator and combustor become coupled and must be solved simultaneously. The isolator slows the flow to subsonic speeds (with respect to the vehicle), and the flow becomes supersonic again at some point in the combustor. The engine code contains a submodel that determines the correct isolator strength that causes the subsonicto-supersonic transition in the combustor to satisfy certain conditions $[14,36]$.

The engine flowpath geometry for MAX-1A is shown in Fig. 5. The engine width is $2.14 \mathrm{~m}$. The combustor geometry consists of a constant-area section followed by another section with a 4 deg divergence angle. The hydrogen fuel is injected from a row of injectors that are located at a single $x$ coordinate $0.14 \mathrm{~m}$ downstream of the start of the combustor, and the injectors are only on one side of the combustor duct. A long combustor (for hydrogen fuel) was selected because of the very high Mach numbers considered and the poor mixing that results from injecting the fuel from a single wall. Each injector has a diameter of $3.45 \mathrm{~cm}$, and they are spaced so that there are $N=14$ injector ports per meter in the $y$ direction. The Mach number at the fuel injector exit is 1.0, and it is assumed that the fuel has a stagnation temperature of $298 \mathrm{~K}$.

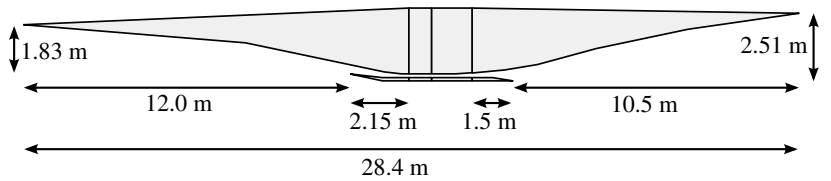

a) Geometry of the full flowpath

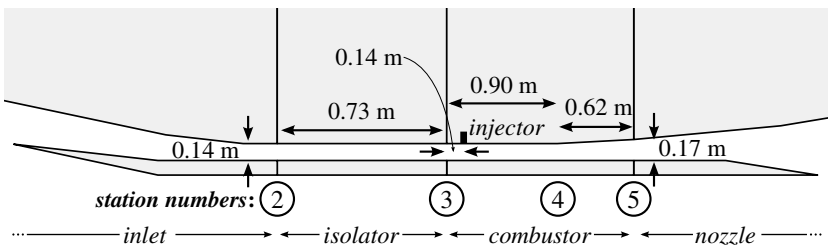

b) Internal flowpath with station numbers

Fig. 5 Schematic of engine MAX-1A flowpath. 


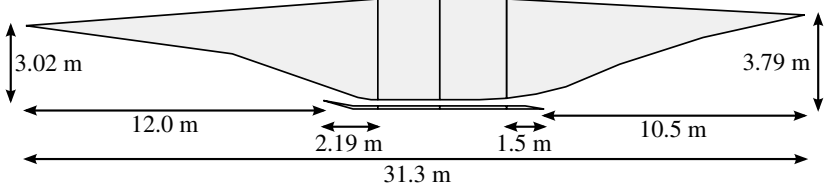

a) Geometry of the full flowpath

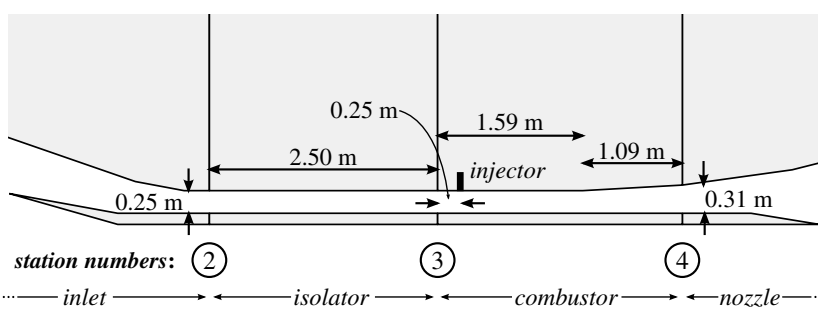

b) Internal flowpath with station numbers

Fig. 6 Schematic of engine MAX-1B flowpath.

Fig. 6 shows the engine geometry for MAX-1B. The engine width, injector diameter, and number of injector ports remain unchanged from the MAX-1A geometry.

\section{External Model}

To calculate the forces on the vehicle's exterior, as shown in Figs. 1 and 2 , we use a modification of the panel method from [16] to include a model for viscous forces. A triangular surface mesh is applied to the vehicle, the freestream velocity is projected onto the surface, and the angle between the freestream and the projected velocity is then used to compute the thermodynamic properties behind either an oblique shock or a Prandtl-Meyer expansion, depending on the sign of the angle. This method is similar in nature to Newtonian impact theory [26] and piston theory [37], in that the pressure is calculated independently for each triangular panel. This method was shown to agree with the hypersonic arbitrary body program to within a few percent, especially for small angles of attack [16], and recent work has also verified the present external aerodynamics model against CFD results [38].

The deflection angle for a triangular surface is calculated by solving

$$
\sin \delta=-\frac{\hat{\boldsymbol{n}}^{b} \cdot \boldsymbol{u}^{b}}{\left\|\boldsymbol{u}^{b}\right\|}
$$

The pressure on the triangle is given by usual oblique shock theory [35] using $M=\boldsymbol{u}^{b} / a_{\infty}$ as the Mach number and $\delta$ as the deflection angle when $\delta$ is positive but less than a certain deflection $\delta_{\max }$. When $\delta>\delta_{\max }$, Newtonian aerodynamics is used as it is known to give good results for large incidence angles.

Boundary-layer thickness and the friction coefficient are computed using the Van Driest II method [39]. Each triangular surface is modeled as a flat plate with an initial boundary-layer thickness determined by the boundary layer of the surfaces that are immediately upstream of it. The boundary layer is assumed to be turbulent on the entire surface of the vehicle.

\section{Mass Properties and Center of Mass}

To provide a first estimate of the mass properties of a hypersonic vehicle, correlations provided by Chudoba [40] are used. These correlations give estimated weights for the vehicle and how much fuel it can carry, and the correlations are dependent on the planform area of the vehicle, design Mach number, and fuel type.

We assume that the mass is distributed evenly throughout the vehicle except for some ballast placed at the nose to shift the center of mass forward. This assumption is used regardless of how much fuel is currently in the vehicle. Table 1 lists the mass properties of the MAX1 A vehicle.

\section{E. Ram-Scram Transition and Unstart Limits}

Ram-scram) transition limits were computed using the method described in [14]. MASIV first attempts to find a purely supersonic combustor solution (scram mode). If none exists, it then uses a shooting method to determine the combustor entrance Mach number such that thermal choking (transition from subsonic to supersonic flow in a ram-mode combustor) is consistent. An incorrect guess for the combustor entrance Mach number will result in either a solution that does not choke (remains subsonic) or has a singularity (namely, $M / x>0$ for $M=1-\varepsilon$ and $M / x<0$ for $M=1+\varepsilon$ ). For each value of combustor entrance Mach number $\left(M_{3}\right)$, there is a corresponding pressure rise that occurs in the isolator region upstream of the combustor. This pressure rise can be computed using formulas from Heiser and Pratt [41]. If the required pressure rise exceeds that of a normal shock, there is no physical solution, and this introduces an incipient steady-state unstart limit, which limits the maximum amount of fuel that can be burned in ram mode.

\section{F. Estimated Accuracy of Models}

Although it is difficult to assess the accuracy of the entire tip-to-tail vehicle model due to the lack of available data, several efforts have been made to estimate the accuracy of individual aspects of the model. These have been reported in the literature. Assessments of the inlet and nozzle models from [11] and [13] were mentioned previously, and their contributions to thrust were found to be accurate to within $6 \%$. However, three-dimensional effects that were not considered may degrade this accuracy somewhat. Assessments of the heat release were made in [12], and ram-scram transition was addressed in [14]. These works indicate errors of less than $15 \%$. Finally, the external aerodynamics was assessed in [38], and the difference between the present model and three-dimensional (3-D) inviscid computational fluid dynamics was less than $15 \%$ for the flight conditions considered here.

\section{Equations of Motion}

For hypersonic vehicles, the velocities and altitude are high enough that the assumption of a flat Earth is no longer valid. As a result, we implement the equations of motion for a rotating ellipsoidal Earth based on a World Geodetic System 1984 (WGS84) shape and gravity model.

The output of the MASTrim hypersonic vehicle model is an acceleration and an angular acceleration in the body frame, which is written as

$$
\dot{x}=f(x, u)
$$

Here, $\boldsymbol{x}$ is a vector of state variables, and $\boldsymbol{u}$ is a vector of control variables. Although MASTrim has been written using general rigidbody six-degree-of-freedom equations of motion, the flight conditions in this paper are all for equatorial flight directly eastward.

\section{A. Trim}

Given a target acceleration $\dot{\boldsymbol{x}}$, finding a trimmed flight condition becomes a problem of finding values of $\boldsymbol{x}$ and $\boldsymbol{u}$ such that Eq. (3) is satisfied. Typically, we define $\boldsymbol{x} \in \mathbb{R}^{n}$ and $\boldsymbol{u} \in \mathbb{R}^{m}$ with $n=12$. If $\boldsymbol{u}$ has $m$ components, the trim problem is a system of 12 equations and

Table 1 Mass properties of vehicle

\begin{tabular}{llc}
\hline \hline Symbol & \multicolumn{1}{c}{ Name } & Value \\
\hline & Operational empty mass & $1.93 \times 10^{4} \mathrm{~kg}$ \\
& Maximum fuel mass & $2.38 \times 10^{4} \mathrm{~kg}$ \\
& gross Mass, takeoff & $4.31 \times 10^{4} \mathrm{~kg}$ \\
$I_{x x}$ & Specific moment of inertia & $2.33 \mathrm{~m}^{2}$ \\
$I_{y y}$ & Specific moment of inertia & $36.23 \mathrm{~m}^{2}$ \\
$I_{z z}$ & Specific moment of inertia & $37.90 \mathrm{~m}^{2}$ \\
$I_{x z}$ & Specific product of inertia & $0.54 \mathrm{~m}^{2}$ \\
$x_{\mathrm{cg}}$ & Center of mass location & $-12.88 \mathrm{~m} \mathrm{~m}$ \\
$z_{\mathrm{cg}}$ & Center of mass location & $0.17 \mathrm{~m}$ \\
\hline \hline
\end{tabular}


$12+m$ variables. It is assumed that the position, velocity, and angular velocity are independently specified. For example, to find a trimmed flight condition at a given velocity and altitude, $V$ and $h$, are determined before the trim analysis is computed. This reduces the problem to six equations and $2+m$ variables. In our case,

$$
\begin{gathered}
\boldsymbol{x}=\left[\begin{array}{llllllllllll}
L & \lambda & h & V & \gamma & \sigma & \phi & \alpha & \beta & P & Q & R
\end{array}\right] \\
\boldsymbol{u}=\left[\begin{array}{llllll}
\mathrm{ER} & \delta_{e} & \delta_{a} & \delta_{r}
\end{array}\right]^{T}
\end{gathered}
$$

so $m=4$. The symbols are defined in the nomenclature section. It is convenient to write the trim equations as

$$
\dot{x}=f(\xi, v)
$$

where

$$
\boldsymbol{\xi}=\left[\begin{array}{llllllllll}
L & \lambda & h & V & \beta & \gamma & \sigma & P & Q & R
\end{array}\right]^{T}
$$

is considered a vector of "fixed" parameters. The independent variables that must be solved for are

$$
\boldsymbol{v}=\left[\begin{array}{llllll}
\alpha & \phi & \mathrm{ER} & \delta_{e} & \delta_{a} & \delta_{r}
\end{array}\right]^{T}
$$

where $\delta_{e}$ is the average of the left and right elevator deflection angles (defined so that a positive deflection moves the trailing edge down), and $\delta_{a}$ is the deflection angle of the right elevator minus the deflection angle of the left elevator.

Evaluating the function $f$ is relatively expensive because it requires calculating the forces and moments on the vehicle, which in turn requires simulating each shock interaction, the fuel-air mixing, As a result, we want to use a method to solve the trim equations that requires as few evaluations of $\boldsymbol{f}$ as possible. We use Broyden's method [42] using a finite-difference approximation to the gradient matrix $\partial \bar{f} / \partial v$ at the initial guess.

\section{B. Ascending Trajectory}

To reduce the ascent problem to an appropriate size, we consider trajectories with constant dynamic pressure. Using an assumed atmospheric model [43] (1976 Standard Atmosphere), the restriction of flying a constant dynamic pressure trajectory allows us to determine altitude as a function of Mach number. In other words, there is a function such that $h=h(V)$. Differentiating this function with respect to time gives

$$
\dot{h}=\frac{\mathrm{d} h}{\mathrm{~d} V} \dot{V}=\frac{\mathrm{d} h}{\mathrm{~d} V} a
$$

Since $\dot{h}=V \sin \gamma$, we can solve for the acceleration

$$
a \frac{\mathrm{d} h}{\mathrm{~d} V}=V \sin \gamma
$$

This enables an optimization problem with two sets of decision variables: $a$ and $h$, both as a function of $V$. Later, when general trajectories are considered, Eq. (10) is used to constrain the flightpath angle $\gamma$.

The initial trajectory results presented in Sec. IV consider trajectories with constant dynamic pressure. This enables further simplification of Eq. (10). The dynamic pressure is $q=\frac{1}{2} \rho V^{2}$, where $\rho$ is given as a function of altitude, $\rho(h)$. Differentiating both sides with respect to altitude gives, for $\dot{q}=0$,

$$
\frac{\mathrm{d} V}{\mathrm{~d} h}=-\frac{V}{2 \rho} \frac{\mathrm{d} \rho}{\mathrm{d} h}
$$

Substituting this result back into Eq. (10) gives

$$
a=-\frac{V^{2}}{2 \rho} \frac{\mathrm{d} \rho}{\mathrm{d} h} \sin \gamma
$$

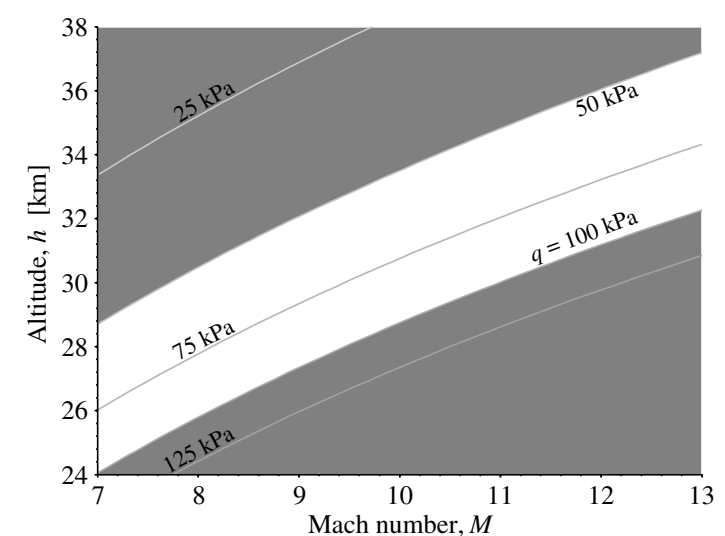

Fig. 7 Contours of dynamic pressure as a function of Mach number and altitude.

This means that $\gamma$ is the main parameter that impacts acceleration. The result is that the entire range of possible flight conditions with a given constant dynamic pressure can be expressed in terms of only two variables, and we use $M$ and $a$ throughout the rest of this paper. Taking another derivative and repeating a similar analysis yields an equation for $\dot{\gamma}$,

$$
\dot{\gamma} \cos \gamma=\left[\frac{\mathrm{d}^{2} h}{\mathrm{~d} V^{2}} a+\left(\frac{\mathrm{d} a}{\mathrm{~d} V}-\frac{a}{V}\right) \frac{\mathrm{d} h}{\mathrm{~d} V}\right] \frac{a}{V}
$$

In this work, the absolute value of the rate of change of the flight path angle never exceeds $0.002 \mathrm{deg} / \mathrm{s}$.

The dynamic pressures as a function of altitude and Mach number are shown in Fig. 7. We consider the normal operating range of dynamic pressures to be between 50 and $100 \mathrm{kPa}$, so the nongrayed portion is the flight corridor used in this paper. For Mach 7 to 13, the highest dynamic pressure resulted in the best performance. Although drag and thrust are both approximately proportional to dynamic pressure, flying at a lower dynamic pressure, and hence higher altitude, means that a higher angle of attack is required, which increases the drag coefficient. Furthermore, since the net thrust is proportional to dynamic pressure, the same thrust coefficient results in a higher acceleration.

\section{Fuel Consumption}

An appropriate objective for a trajectory that must connect two fixed flight conditions is the total fuel usage. In this section, we describe a method to calculate the total fuel consumption for a trajectory without directly considering time. Similar approaches can be found in [8], in which the equations of motion were written in terms of downrange distance; and [2], where it was shown that the fuel consumption could be calculated using energy as a variable of integration. In the present work, we use velocity as the dependent variable and eliminate time completely from the simulation. If time is used as a variable, the total fuel used is defined as

$$
m_{f}(t)=\int_{0}^{t} \dot{m}_{f}\left(V(\tau), a(\tau), m_{f}(\tau)\right) \mathrm{d} \tau
$$

Both the instantaneous rate of fuel consumption $\dot{m}_{f}$ and the total fuel consumption $m_{f}$ are defined to be positive.

Suppose that a given trajectory is parameterized by $n$ pairs of flight conditions $\left(M_{1}, a_{1}\right), \ldots,\left(M_{n}, a_{n}\right)$, and let $V_{1}, \ldots, V_{n}$ be the velocities corresponding to the Mach numbers $M_{1}, \ldots, M_{n}$. A simple change of variables $(\mathrm{d} V=a \tau \mathrm{d})$ transforms Eq. (13) into

$$
m_{f}=\int_{V_{1}}^{V_{n}} \frac{\dot{m}_{f}\left(V, a(V), m_{f}(V)\right)}{a(V)} \mathrm{d} V
$$

Using trapezoidal numerical integration, this integral can be estimated as 


$$
m_{f}=\sum_{i=1}^{n-1} \frac{1}{2}\left(\frac{\dot{m}_{f, i}}{a_{i}}-\frac{\dot{m}_{f, i+1}}{a_{i+1}}\right)\left(V_{i+1}-V_{i}\right)
$$

This formulation allows the total fuel consumption to be calculated without a time-domain simulation, but it is still necessary to calculate the time spent on each trajectory segment. We assume that the acceleration is piecewise linear in time:

$$
\begin{gathered}
a(t)=a_{i}+\left(a_{i+1}-a_{i}\right) \frac{t-t_{i}}{\Delta t_{i}} \\
V(t)=V_{i}+a_{i}\left(t-t_{i}\right)+\frac{1}{2}\left(a_{i+1}-a_{i}\right) \frac{\left(t-t_{i}\right)^{2}}{\Delta t_{i}}
\end{gathered}
$$

Setting $V\left(t_{i+1}\right)=V_{i+1}$ yields

$$
\Delta t_{i}=2 \frac{V_{i+1}-V_{i}}{a_{i+1}+a_{i}}
$$

\section{Direct Optimization of Acceleration Profile}

The form of Eq. (14) suggests a variational approach to minimizing the total fuel consumption. In such an approach, the goal is to select a function $a^{*}(V)$ that minimizes $m_{f}\left(V_{n}\right)$. According to a standard calculus of variations argument,

$$
\left.\frac{\partial}{\partial \varepsilon} m_{f}\left(a^{*}+\varepsilon \delta a\right)\right|_{\varepsilon=0}=0
$$

for any perturbation $\delta a$ to the optimal trajectory. Let us assume for the moment that the fuel mass flow rate $\dot{m}_{f}$ does not depend on changes in the vehicle mass (i.e., $\partial \dot{m}_{f} / \partial m_{f}=0$ ). Then, applying the variational principle to Eq. (14) leads to the condition

$$
\frac{\partial \dot{m}_{f}}{\partial a^{*}}=\frac{\dot{m}_{f}}{a^{*}}
$$

which must be satisfied for all velocities $V \in\left[V_{1}, V_{n}\right]$. This is an indirect approach because it reduces the optimization problem to solving an algebraic equation for each velocity.

The direct approach for a discretized geometry is to minimize the total fuel consumption as presented in Eq. (15). The decision variables are $a_{1}, \ldots, a_{n}$, and thus the optimization is a straightforward nonlinear programming problem. It is possible to gain more insight about the problem by looking at the optimality conditions. Taking the derivative of Eq. (15) with respect to $a_{i}$ gives

$$
\frac{\partial m_{f}}{\partial a_{i}}=\left(\frac{\partial \dot{m}_{f, i}}{\partial a_{i}}-\frac{\dot{m}_{f, i}}{a_{i}}\right) \frac{V_{i+1}-V_{i}}{2 a_{i}}
$$

and setting this equal to zero gives

$$
\frac{\partial \dot{m}_{f, i}}{\partial a_{i}}=\frac{\dot{m}_{f, i}\left(a_{i}, m_{f, i-1}\right)}{a_{i}}
$$

Therefore, the continuous and discrete problems both give very similar optimality conditions, and notice that the derivation of the discrete result [Eq. (20)] did not make the assumption that $\partial \dot{m}_{f} / \partial m_{f}=0$. Equation (20) does provide a simple method to find the optimum fuel acceleration $a_{i}$ at each velocity step, but it cannot be used to solve for all $a_{1}, \ldots, a_{n}$ simultaneously. The reason is that the equation for $a_{i}$ depends on the mass at the previous step, $m_{f, i-1}$, which depends on the previous accelerations $a_{1}, \ldots, a_{i-1}$. Thus it is possible to solve for the acceleration values sequentially.

\section{Results}

The results in this section begin with computed operating maps, which show how fuel consumption relates to flight condition variables in Sec. IV.A. Then, in Sec. IV.D, optimized trajectories for scram-mode operation (Mach 7 to 13) are described, and the sensitivity of these trajectories is discussed in Sec. IV.C. Results in Sec. IV.D described optimized trajectories through ram-scram transition (Mach 4 to 7). Because the code does not require highfidelity CFD or other computationally expensive techniques, it was possible to explore a large design space and evaluate the vehicle's performance. The model additionally provides insights on operational limits such as combustion efficiency, ram-scram transition, and many others.

The analysis in this section can be split into creation of engine operability maps, scram trajectory optimization, sensitivity analysis, and ram-scram trajectory optimization. In the present discussion, operating maps consist of a tabulation of the trim variables (i.e., $v$ from Sec. III.A) for a range of flight conditions. Using these operating maps simplifies the performance calculation for a trajectory, and the maps are used for the fuel-minimization problem that follows. In addition to finding the trajectory that minimizes total fuel consumption subject to the constraints, we also compare fuel usage between the trajectories.

Plots of the various trim variables are given along the optimum trajectories, and these are compared to the results along constantacceleration trajectories. This provides both an idea of how much fuel is saved by following the optimized trajectory and what the trends are that are guiding the minimization of the trajectory. Finally, the more challenging problem of optimizing a trajectory that includes ram-toscram transition is addressed. The proposed model predicts a higher specific impulse in ram mode, which leads to preference of trajectories that remain in ram mode longer. It is shown that the usual heuristic of flying at the maximum allowable dynamic pressure is not optimum for such trajectories.

\section{A. Operating Maps, Mach 7 to 13}

In the current work, we characterize the flight conditions in terms of the flight Mach number $M$, the vehicle linear acceleration $a$, the dynamic pressure $q$, and the fullness fraction of the fuel tanks $f$.

Consider a trajectory in which a vehicle accelerates from Mach 7 to Mach 13 with a constant dynamic pressure of $100 \mathrm{kPa}$. Figure $\underline{8}$ shows two operating maps for the flight conditions along this trajectory with an acceleration between 0 and $6 \mathrm{~m} / \mathrm{s}^{2}$. For example, a vehicle that flies with a constant acceleration of $2 \mathrm{~m} / \mathrm{s}^{2}$ corresponds to moving from left to right along the horizontal line $a=2 \mathrm{~m} / \mathrm{s}^{2}$ in Fig. 8a. Along this example trajectory, the equivalence ratio increases from a value that is less than unity to a value greater than unity. The solid black lines are for the case that the vehicle has full fuel tanks $(f=1)$, and the dashed gray lines show the trim conditions for the case that the fuel tanks are empty $(f=0)$. As the vehicle flies, fuel is consumed, and the mass of the vehicle decreases. The difference in mass of the vehicle can be substantial (more than 50\%; see Table 1), and as a result, the fully fueled vehicle has a higher trim angle of attack. The higher angle of attack results in more drag and approximately twice as much fuel consumption.

The inlet is designed for flight conditions with an angle of attack in the range $[-0.5 \mathrm{deg},+1.0 \mathrm{deg}]$ and a Mach number in the range of $7-11$. Figure $8 \mathrm{~b}$ shows that there is an identifiable boundary around $M=11.5$ when the trends in the operating map change or even reverse. This boundary does not line up exactly with $M=11$ because raising the angle of attack has a similar effect on the inlet shock patterns to lowering the Mach number.

Figure 8 a shows the equivalence ratio at the various trimmed flight conditions. The equivalence ratio determines how much fuel is injected; it does not directly state how much fuel burns. For example, if the equivalence ratio is 1.0 and only half of the fuel burns, the model indicates that injecting more fuel will increase the amount of fuel that burns. This explains the high equivalence ratios in Fig. 8a; the amount of fuel that actually burns is always below the stoichiometric value. In the code, fuel is injected as a jet in crossflow, and burning is limited by 


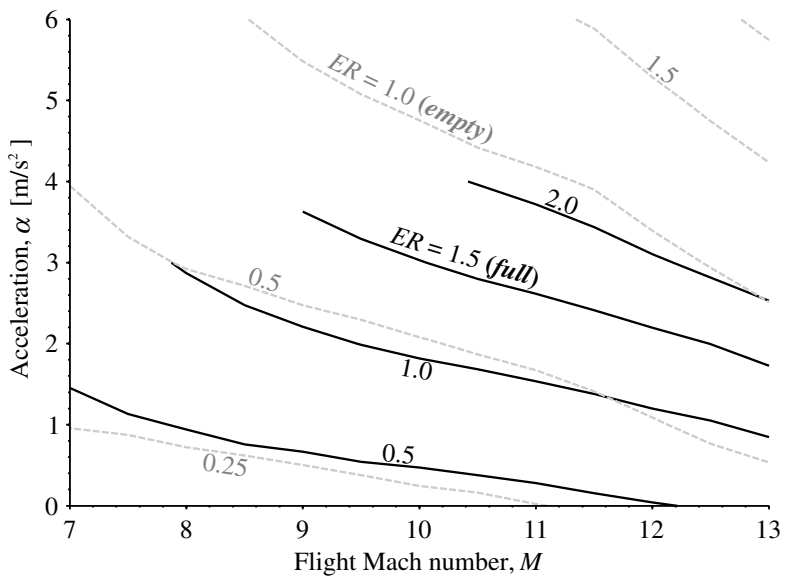

a) Equivalence ratio $(E R)$

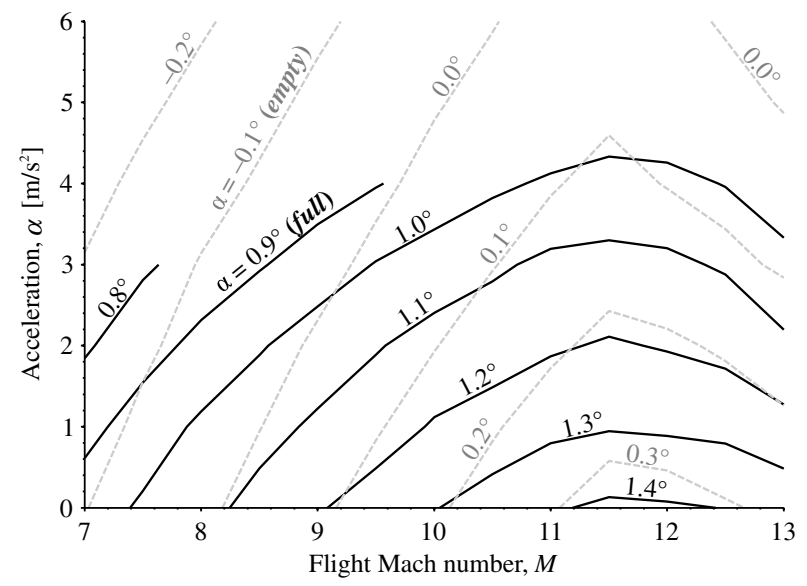

b) Angle of attack $(\alpha)$

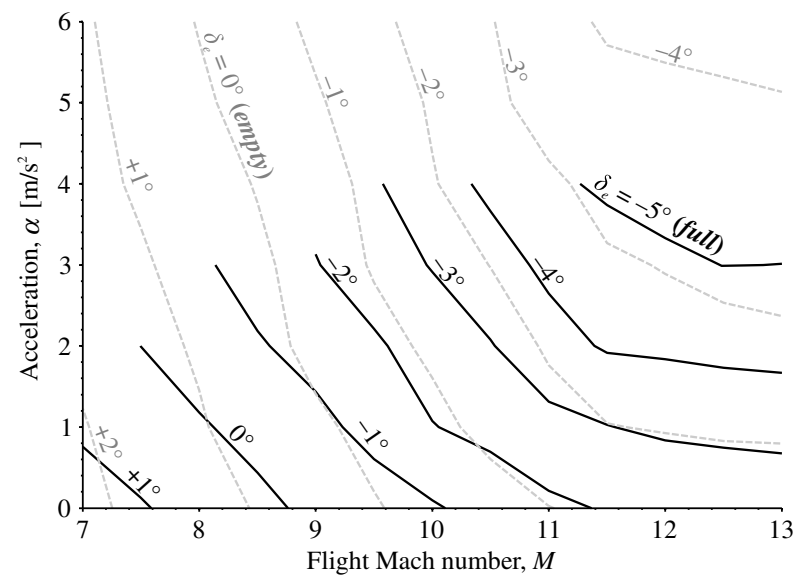

c) Elevon angle $\Delta_{e}$; a trailing-edge-down deflection is positive

Fig. 8 Trimmed scram-mode flight conditions with $q=100 \mathrm{kPa}$. Solid black lines are for full fuel tanks, and dashed gray lines are for empty fuel tanks.

finite-rate chemistry, so incomplete mixing and burning do occur. Figure 8 a shows that a larger equivalence ratio is required to achieve higher accelerations, but the equivalence ratio also increases with Mach number. This is primarily due to the less efficient combustion at higher Mach numbers, which is a well-known property of airbreathing propulsion systems.

It can be seen in Fig. $8 \mathrm{~b}$ that the trim angle of attack decreases if the Mach number is increased while holding the acceleration constant. This is caused by the decrease in lift coefficient that is associated with increasing Mach number for supersonic flow. Although the static pressure on the surface increases, it increases slower than $M^{2}$, and thus the lift coefficient decreases. However, the trim angle of attack in Fig. 8 b decreases for Mach numbers above 11, which is a result of shock interactions caused by the external shocks entering into the internal flow. These shock interactions cause a marked increase on the drag and thus changes to the entire trim condition.

Spillage, which is typically viewed as inefficient performance because it decreases the amount of fuel that can be burned in the combustor, is a measure of the difference between the actual and ideal mass flow into the engine and is one factor in scramjet performance. The maximum mass capture is defined here as the airflow that would be captured when the bow shock exactly hits the leading edge of the cowl. Figure 9 shows a visualization of flow spillage. A fortunate, but often overlooked, consequence of spillage is that it provides extra lift. This extra lift comes from the downward component of the spilled airflow, and the spillage also causes the shock pattern in the inlet to change such that the pressures on the vehicle underside are increased. In short, spillage causes has both undesirable (lower airflow to the engine) and positive (extra lift) consequences. In the present work, spillage has a small effect on the trajectory optimization because the decision variable (acceleration) has only a small effect on the spillage. However, spillage would be a more important consideration in the optimization of the vehicle design. In addition, the spillage will be significantly different (and usually higher) if a 3-D analysis is performed.

The fact that the trim angle of attack decreases as the acceleration $a$ increases is a consequence of the increasing equivalence ratio. More heat addition in the combustor leads to more lift from the nozzle, so a lower angle of attack results. The same logic explains the decreasing elevator angle seen in Fig. 8c because the extra lift is coming from the nozzle creates a nosedown pitching moment that counteracts the moment from the inlet. This causes the required $\delta_{e}$ to decrease.

\section{B. Minimum-Fuel Trajectories, Mach 7 to 13}

One possible trajectory is to fly at a constant acceleration of $2 \mathrm{~m} / \mathrm{s}^{2}$, which would be a horizontal line in Fig. $\underline{8}$, but such a

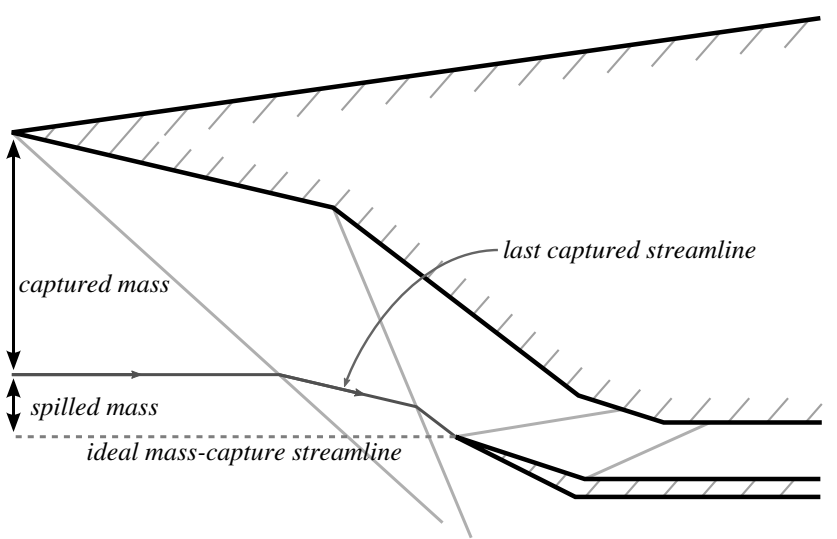

Fig. 9 Sketch of definition of inlet flow spillage. 


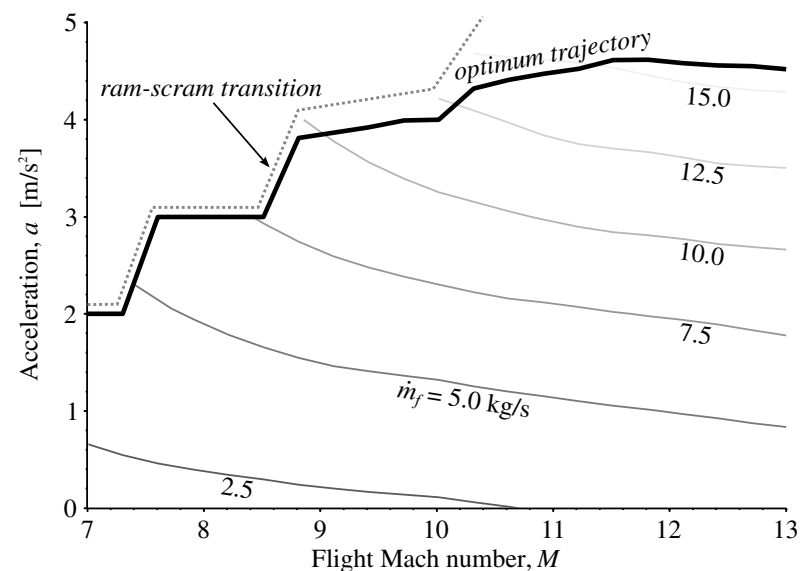

Fig. 10 Minimum-fuel trajectory plotted with fuel mass flow rate contours. The dynamic pressure is $100 \mathrm{kPa}$.

trajectory is not optimal. The next goal is to compute an acceleration profile that minimizes fuel usage. The constraints are that the dynamic pressure is constant at $100 \mathrm{kPa}$, the starting and end points are Mach 7 and 13, respectively, and only scram-mode solutions are considered. At the initial condition, $M=7$, the fuel tanks are full, so the appropriate conditions are shown by the black lines in Fig. 8. To make sure that the trim calculations are consistent with the mass of the vehicle throughout the trajectory, trim calculations were performed for 11 different values of fuel mass, which results in a three-variable surrogate for the flight envelope of the vehicle.

Following the discussion in Sec. III.D, the goal is to choose accelerations $a_{1}, \ldots, a_{n}$ at $n$ different velocities along the trajectory. It is expected that an acceleration near the maximum attainable, which minimizes time overcoming the drag on the vehicle, will be optimal. The objective function is Eq. (15), and direct optimization was performed for the results in this section.

Figure 10 shows the solution of this fuel minimization problem for the $q=1 \overline{00} \mathrm{kPa}$ case. The trajectory showed good convergence with respect to $n$, the number of trajectory segments, but was affected by the choice of initial condition. To ensure that the optimum trajectory shown is at or near a global optimum, many initial acceleration profiles were used. In line with previous results $[\underline{7}, \underline{8}]$ and the previous prediction, the optimum was close to the maximum acceleration throughout the trajectory. The difference is that the maximum acceleration no longer corresponds to an equivalence ratio of unity. Between Mach 7 and Mach 9, the maximum acceleration is constrained by thermal choking in the combustor, which can be seen from the fact that the optimized trajectory is close to the ram-scram transition boundary (dotted line). At higher Mach numbers, the acceleration is limited by the oxygen available to the engine, but this occurs at equivalence ratios greater than unity due to incomplete combustion.

Figure 11 shows a plot of two variables along the minimum-fuel path and along several constant-acceleration trajectories. The expected result for a fuel-minimizing trajectory would be that the equivalence ratio stays near 1.0 or just above. However, the equivalence ratio in Fig. 11a goes notably higher than unity, which means that more fuel is being injected than could possibly burn in the combustor due to the stoichiometric limit. For hydrogen fuel, rich mixtures tend to increase the specific impulse up to a point due to the low molecular weight of the fuel. In this case, there is an additional factor that contributes to the high equivalence ratios.

Recall that there is no guarantee that all of the fuel injected into the flow actually burns. If there is still more oxygen available at a given condition, increasing the equivalence ratio should increase the amount of fuel that burns up to the limit where all of the oxygen is used. This is true even if the equivalence ratio is already 1 or higher. Therefore, we look at how much oxygen is present at the downstream boundary of the combustor, which is shown in Fig. 11b.

The result of this analysis is that the maximum-acceleration trajectory is the one that injects enough fuel to burn all or nearly all of the oxygen available except at lower Mach numbers where the acceleration is limited by thermal choking. Looking at Figs. 11a and $11 \mathrm{~b}$, one can see that the combustion is efficient (i.e., burns most of the fuel) at lower Mach numbers but quite inefficient at higher Mach numbers. For instance, at Mach 9 with $a=3 \mathrm{~m} / \mathrm{s}^{2}$, the equivalence ratio is about 1.0, and the mass fraction of oxygen remaining is 0.02 , which indicates a combustion efficiency of about $90 \%$. At Mach 13 with an acceleration $a=3 \mathrm{~m} / \mathrm{s}^{2}$, the equivalence ratio is about 1.6 while there is still $\mathrm{O}_{2}$ remaining (a mass fraction of about 0.035). With oxygen still available, adding more fuel could lead to greater heat release, but only if the extra fuel adequately mixes with the airstream. Based on these results, it appears that rockets may be a better option than airbreathing propulsion for Mach numbers higher than about 10 .

In some cases, the discrete optimality condition of Eq. (20) is met at an acceleration slightly below the maximum. This can be seen for Mach numbers greater than 10 in Fig. 10. This represents essentially a point of diminishing returns, where adding more fuel does increase the acceleration, but not efficiently enough to justify the extra fuel consumption.

\section{Sensitivity of Fuel Consumption}

This subsection compares total fuel consumption and several different trajectories to investigate the sensitivity of the objective function to trajectory design. In addition to the constant-acceleration trajectories of Fig. 11, two lower values of the dynamic pressure $(q=75 \mathrm{kPa}$ and $q=50 \mathrm{kPa})$ are considered. For all three dynamic pressures, the same range of Mach numbers is used. Holding the

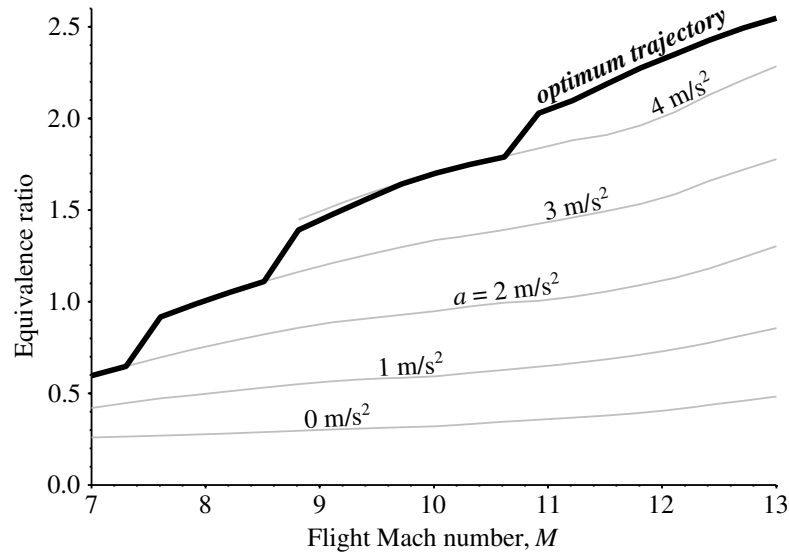

a) Equivalence ratio

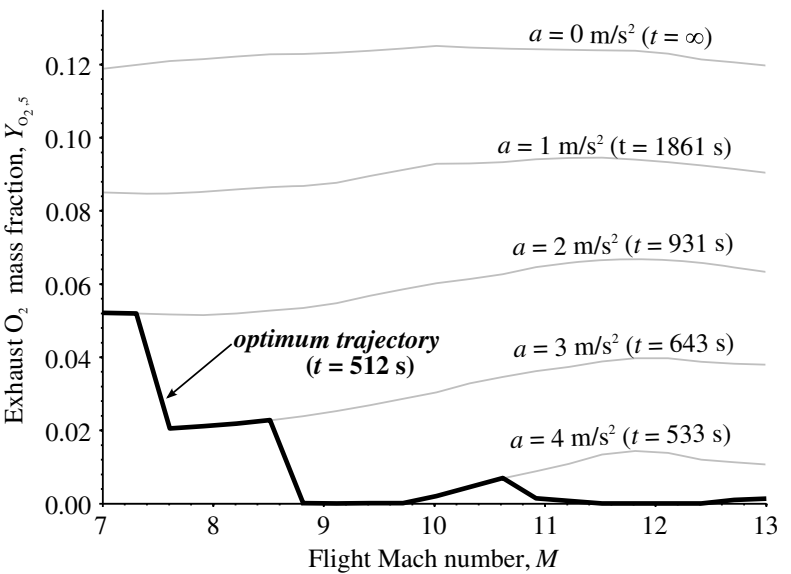

b) Combustor exhaust $\mathrm{O}_{2}$ mass fraction $\left(\mathrm{Y}_{\mathrm{O}_{2}, 5}\right)$

Fig. 11 State variables along minimum-fuel trajectory (thick line) and constant-acceleration trajectories (thin lines). The total time to accelerate from Mach 7 to 13 is in parentheses. 


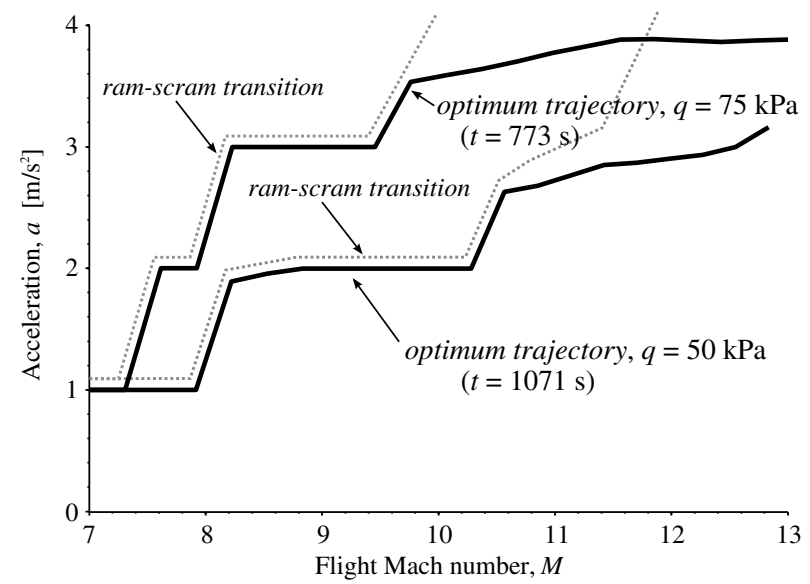

Fig. 12 Minimum-fuel acceleration profiles (thick lines) for two different dynamic pressures. Time to fly each trajectory shown in parentheses.

Mach number constant, a decrease in dynamic pressure is equivalent to an increase in altitude.

Figure 12 shows the optimized trajectories for dynamic pressures of $50 \mathrm{kPa}$ and $75 \mathrm{~Pa}$. The MAX-1A vehicle does not perform well at a dynamic pressure of $50 \mathrm{kPa}$. In fact, it was not possible to trim the vehicle with a positive acceleration with full fuel tanks, so the trajectories at $q=50 \mathrm{kPa}$ assume that the fuel tanks are only $70 \%$ full at Mach 7. This was the highest vehicle mass for which an acceleration of at least $1 \mathrm{~m} / \mathrm{s}^{2}$ could be maintained in scram mode.

To test if the optimum trajectories were near the maximum acceleration, we can check the plots of oxygen remaining at the downstream boundary of the combustor. These are shown in Fig. 13. Except for a small region between Mach 9 and 11 in for the $q=$ $75 \mathrm{kPa}$ trajectory, both optimum trajectories are at or near the maximum scram-mode acceleration. For lower Mach numbers, the acceleration is limited by thermal choking (i.e., it is the highest scram-mode acceleration, although higher accelerations may be attainable in ram mode), and at higher Mach numbers, availability of oxygen for combustion is the limiter. The bump in the optimum trajectory of Fig. 13 between Mach 9 and 11 is an artifact of the surrogate. In this range, the vehicle cannot accelerate at $3 \mathrm{~m} / \mathrm{s}^{2}$ without transitioning to ram mode, so it treats the maximum acceleration as $2 \mathrm{~m} / \mathrm{s}^{2}$. In reality, an acceleration of around $2.3 \mathrm{~m} / \mathrm{s}^{2}$ would remain in the scram mode.

The primary difference among the three values for dynamic pressure seems to be that the vehicle can accelerate faster at higher dynamic pressures. There are two main reasons for this. For a fixed vehicle mass, a lower dynamic pressure means that a higher lift

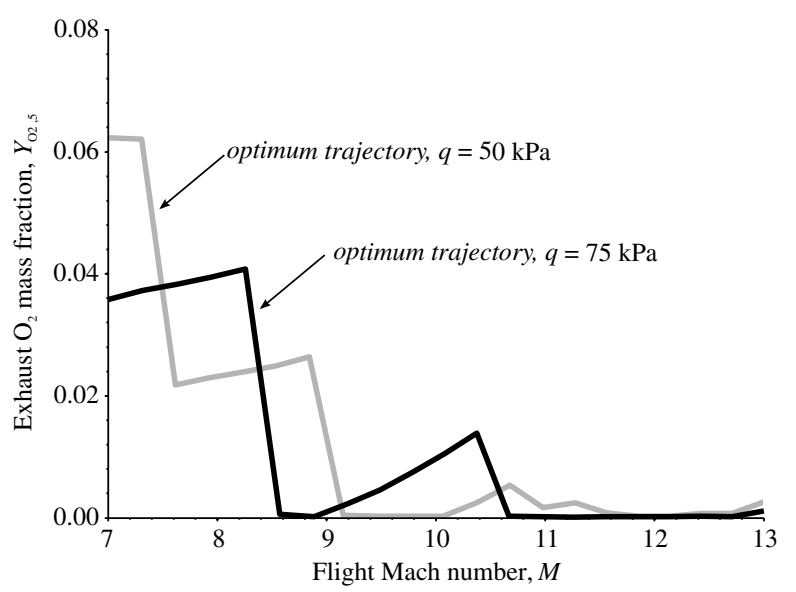

Fig. 13 Oxygen mass fraction in the combustor exhaust $\left(Y_{O_{2}, 5}\right)$ for optimized trajectories at two dynamic pressures.

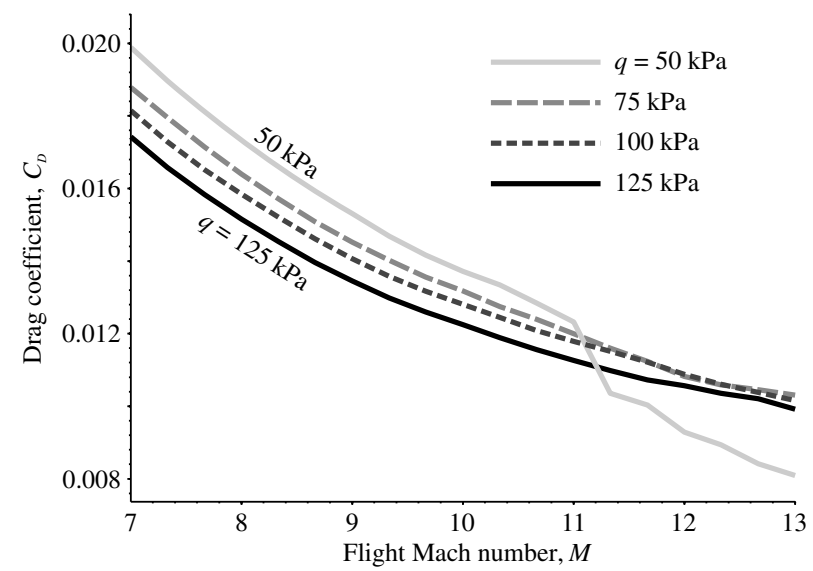

Fig. 14 Vehicle drag coefficient for the optimum trajectory at four dynamic pressures.

coefficient is needed to satisfy trim conditions. The result is a higher drag coefficient, and thus a lower maximum acceleration.

The second reason that the maximum acceleration is lower for lower dynamic pressures is that the net force on the vehicle is basically proportional to the dynamic pressure. The acceleration of the vehicle is given approximately by

$$
m a \approx q S\left(C_{T}-C_{D}\right)
$$

where $C_{T}$ is the thrust coefficient, and $S$ is a reference area. The previous argument showed that $C_{D}$ increases when $q$ decreases, and so a higher thrust coefficient is needed. If thrust is greater than drag, a fixed value of $C_{T}-C_{D}$ results in a lower acceleration for a lower value of $q$. So even if the thrust and drag coefficients were unaffected by dynamic pressure, we would expect a higher maximum acceleration at higher dynamic pressures.

Figures 14 and 15 show the vehicle drag coefficient and specific impulse, respectively, for the optimum trajectory at four dynamic pressures. The drag is defined as the net force on the vehicle in the direction of the relative wind excluding the forces on the inlet, isolator, combustor, and nozzle. For the specific impulse calculation, the thrust is defined as the component of the forces on the inlet, isolator, combustor, and nozzle parallel to the centerline of the combustor and isolator.

The specific impulse, which is defined as the thrust per kilograms of fuel divided by $9.8 \mathrm{~m} / \mathrm{s}^{2}$, is shown in Fig. 15. The plot shows the expected decreasing trend as the Mach number increases, but a more interesting result is that the specific impulse is slightly higher at higher dynamic pressures. Actual thrust numbers decrease slightly

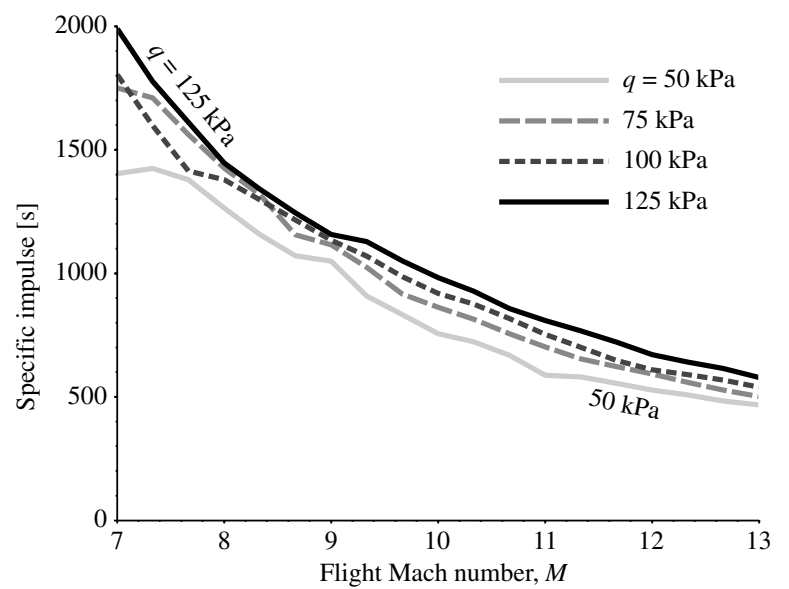

Fig. 15 Specific impulse for the optimum trajectory at four dynamic pressures. 
Table 2 Fuel usage for several trajectories at four dynamic pressures

\begin{tabular}{lcccc}
\hline \hline Trajectory & $50 \mathrm{kPa}^{\mathrm{a}}$ & $75 \mathrm{kPa}$ & $100 \mathrm{kPa}$ & $125 \mathrm{kPa}$ \\
\hline $\begin{array}{l}\text { Minimum } \\
\text { fuel }\end{array}$ & $5639.9 \mathrm{~kg}^{\mathrm{a}}$ & $6032.1 \mathrm{~kg}$ & $5368.1 \mathrm{~kg}$ & $5062.3 \mathrm{~kg}$ \\
Maximum $a$ & $5639.9 \mathrm{~kg}^{\mathrm{a}}$ & $6038.8 \mathrm{~kg}$ & $5377.1 \mathrm{~kg}$ & $5066.9 \mathrm{~kg}$ \\
$a=1 \mathrm{~m} / \mathrm{s}^{2}$ & $6056.5 \mathrm{~kg}^{\mathrm{a}}$ & $7836.9 \mathrm{~kg}$ & $7142.7 \mathrm{~kg}$ & $7288.4 \mathrm{~kg}$ \\
$a=2 \mathrm{~m} / \mathrm{s}^{2}$ & $5772.2 \mathrm{~kg}$ & $6424.1 \mathrm{~kg}$ & $5938.1 \mathrm{~kg}$ & $5719.4 \mathrm{~kg}$ \\
& $(8.5)^{\mathrm{ab}}$ & $(7.5)^{\mathrm{b}}$ & & \\
$a=3 \mathrm{~m} / \mathrm{s}^{2}$ & - & $6049.1 \mathrm{~kg}$ & $5553.8 \mathrm{~kg}$ & $5311.7 \mathrm{~kg}$ \\
& & $(9.0)^{\mathrm{b}}$ & $(7.5)^{\mathrm{b}}$ & \\
$a=4 \mathrm{~m} / \mathrm{s}^{2}$ & - & - & $5380.7 \mathrm{~kg}$ & $5162.4 \mathrm{~kg}$ \\
& & & $(9.5)^{\mathrm{b}}$ & $(7.5)^{\mathrm{b}}$ \\
\hline \hline
\end{tabular}

aThese trajectories are initialized $70 \%$ of the maximum fuel mass at Mach 7.

${ }^{\mathrm{b}}$ The number in parentheses indicates minimum Mach number for which acceleration is achievable. Lower accelerations are used for lower Mach numbers.

with Mach number from 21 to $19 \mathrm{kN}$ as the Mach number increases at a dynamic pressure of $100 \mathrm{kPa}$. At $q=50 \mathrm{kPa}$, the thrust is about $4 \mathrm{kN}$ less throughout the trajectory. The reduced drag coefficient in the inlet is partially responsible for this trend; another reason is likely that the static pressure in the combustor is much higher at higher dynamic pressures. Higher-pressure combustion leads to improved thermal efficiencies in many types of engines. It should be noted that the numerical value of the specific impulse is sensitive to the definition of the thrust force.

To see how much the choice of trajectory affects the total fuel consumption, Table 2 gives a comparison of the minimum-fuel trajectories and several constant-acceleration trajectories for four dynamic pressures. A dynamic pressure of $125 \mathrm{kPa}$ is included to show the effect on the engine of further dynamic pressure increases outside the flight corridor. Table 2 reports that the total fuel consumption is about 5000 or $6000 \mathrm{~kg}$, while the total fuel available from Table 1 is about 23 tons. The remaining fuel can be used to accelerate to Mach 7, especially during the inefficient afterburner mode that must be used from takeoff until a Mach number where rammode operation is possible. However, analysis of this initial portion of the flight was not performed.

As mentioned in the previous discussion, the MAX-1A vehicle was not able to sustain a positive acceleration with full fuel tanks for the $q=50 \mathrm{kPa}$ case, so those trajectories are initialized with the tanks $70 \%$ full. This causes a reduction in drag due to lift compared to the other trajectories because the vehicle is lighter, and this is the reason that the $q=50 \mathrm{kPa}$ fuel consumption numbers are lower than the $q=75 \mathrm{kPa}$ numbers.

It is known that the trajectory design has a significant effect on the total fuel consumption because choosing a low acceleration causes the total fuel consumption to go to infinity. This can be seen from Eq. (15), for example. However, the effect of finding an optimized trajectory compared to a simpler choice such as a constant acceleration remains to be seen. As expected, increasing the dynamic pressure reduces the total fuel consumption, and a low acceleration of $a=1 \mathrm{~m} / \mathrm{s}^{2}$ requires significantly more fuel than higher-acceleration trajectories. However, further increasing the acceleration from 2 to $3 \mathrm{~m} / \mathrm{s}^{2}$ only reduces the fuel consumption a relatively small amount.

Table $\underline{2}$ also shows that the optimized trajectory saves very little fuel compared to the much simpler maximum-acceleration trajectory. For the lowest dynamic pressure, the optimized trajectory was the maximum-acceleration trajectory. This indicates that the maximum acceleration is a good heuristic for trajectory optimization when flying scram-mode trajectories. This means selecting an equivalence ratio so that the Mach number at the end of the constant-area section is just above unity $\left(M_{4}=1\right.$; see Fig. $5 \mathrm{~b}$ ) when the maximum acceleration is limited by thermal choking and an equivalence ratio so that the oxygen is almost completely burned $\left(Y_{\mathrm{O}_{2}, 5}=0\right)$ otherwise. Finding such a trajectory will still require preflight calculations because both of these quantities $\left(M_{4}\right.$ and $\left.Y_{\mathrm{O}_{2}, 5}\right)$ cannot be measured in flight.

\section{Minimum-Fuel Trajectories with Ram-Scram Transition, Mach 4.5 to 7}

Trajectories that include conditions in both ram and scram modes may be significantly more complex than ram-only or scram-only trajectories. In this section, acceleration from Mach 4.5 to Mach 7 is considered, which is a range of Mach numbers traditionally associated with transition from ram mode to scram mode. A slightly different vehicle configuration (the MAX-1B vehicle) is used for this section to increase the performance at lower Mach numbers. Design of a vehicle to operate efficiently from Mach 4.5 to Mach 13 (if such a vehicle would even be practical) is a challenging problem that is not addressed here.

Figure 16 shows optimized acceleration profiles for constant dynamic pressures of 100 and $55 \mathrm{kPa}$; the acceleration profiles were calculated using the same methods described in previous sections. The unstart limit plotted in Fig. 16b was computed using the method described in Sec. II.E. The transition from ram mode to scram mode is marked on the operating map as the dashed line, and it can be seen that transition (where the optimized trajectory crosses the dotted transition line) does not occur at the same Mach number for the two trajectories. The transition boundary was computed using methods described in [14]. This has a significant effect on the total fuel consumption because the engine tends to perform better in ram mode due to increased mixing and longer residence times of the subsonic flow in the combustor.

Furthermore, flying at a lower dynamic pressure (higher altitude) tends to cause the engine to remain in ram mode to a higher Mach number. As there is less air flowing into the engine at higher altitudes, the equivalence ratio required to maintain a certain acceleration is more likely to thermally choke the flow, which leads to subsonic flow (ram-mode operation) and increased thrust. Thus, a higher-altitude (lower dynamic pressure) trajectory may consume less fuel simply by remaining in ram mode longer. Optimization of the acceleration profile was performed for 11 values of the dynamic pressure, and the results are shown in Fig. 17. In fact the lowest total fuel consumption

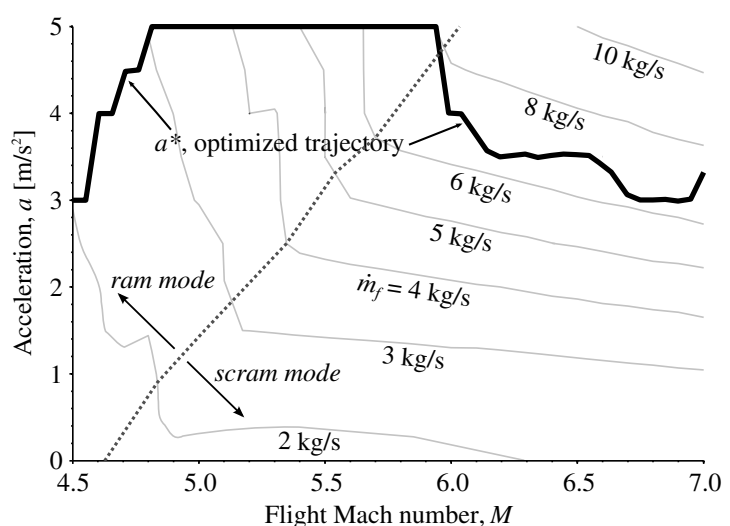

a) $q=100 \mathrm{kPa}$

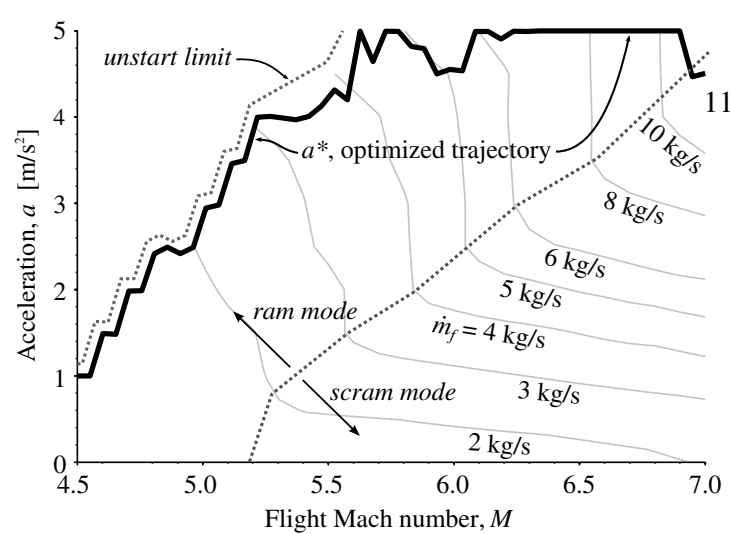

b) $q=55 \mathrm{kPa}$

Fig. 16 Optimized acceleration profiles for trajectories with constant dynamic pressure at $q=100 \mathrm{kPa}$ and $q=55 \mathrm{kPa}$. 


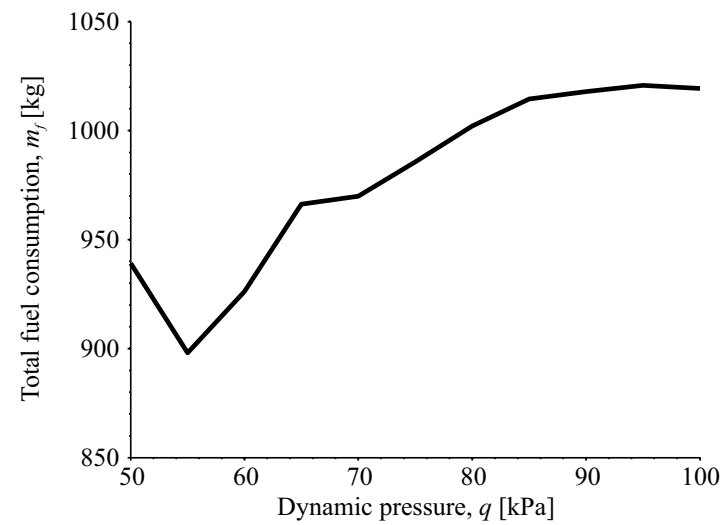

Fig. 17 Total fuel consumption for constant dynamic pressure trajectories with optimized acceleration profiles.

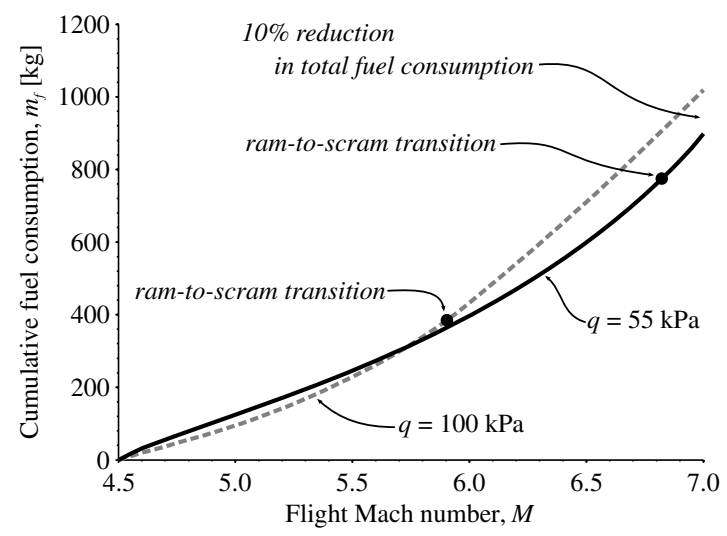

a) Cumulative fuel consumption $\left(m_{f}\right)$

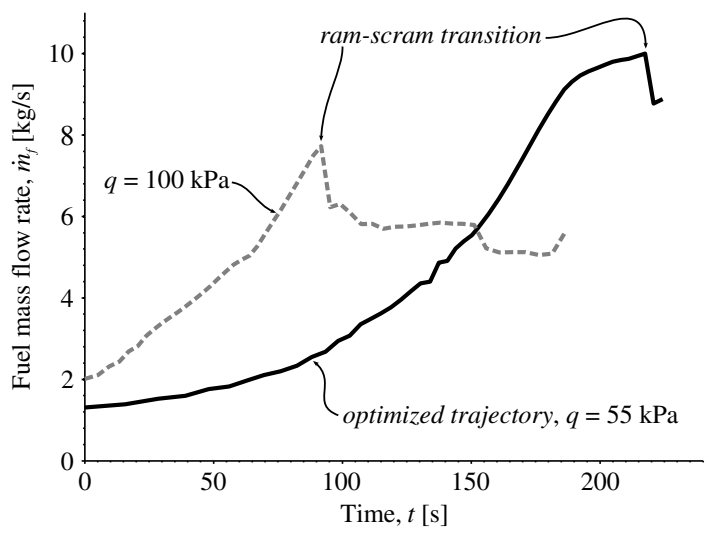

b) Fuel mass flow rate $\left(\dot{\boldsymbol{m}}_{f}\right)$

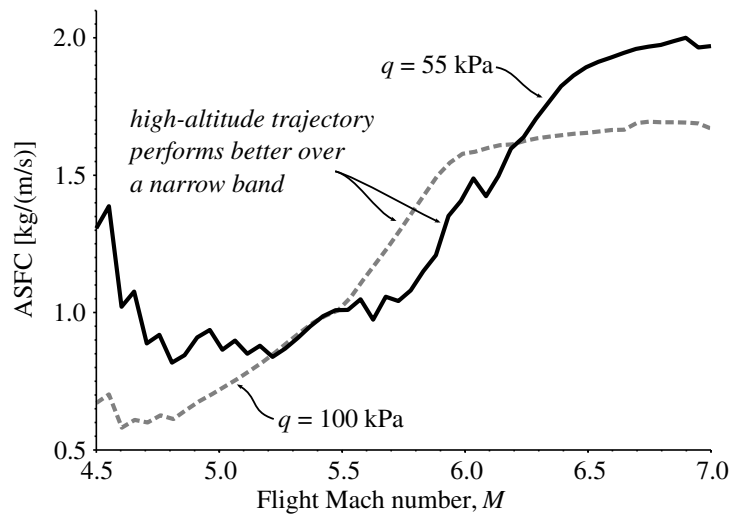

c) Acceleration-specific fuel consumption (ASFC),

i.e., fuel consumed per change in velocity of $1 \mathrm{~m} / \mathrm{s}^{2}$

Fig. 18 Optimized trajectories for two constant dynamic pressures, $q=55 \mathrm{kPa}$ and $q=100 \mathrm{kPa}$.
(898 kg) occurred with the dynamic pressure set at $55 \mathrm{kPa}$, which corresponds to the trajectory in Fig. 16b.

In Fig. 18, a more detailed comparison is made between the $55 \mathrm{kPa}$ trajectory and the $100 \mathrm{kPa}$ (lower altitude) trajectory. Fig. 18a shows the cumulative fuel consumption along the two trajectories. Notice that the higher dynamic pressure (gray dotted curve) consumes less fuel for the initial portion of the trajectory (from Mach 4.5 to Mach 5.5 ), but the lower dynamic pressure (solid black curve) remains in ram mode longer and consumes less fuel over the latter portion of the trajectory. The difference in the final values of these two curves corresponds to a $12 \%$ decrease in fuel consumption (from 1019 to $898 \mathrm{~kg}$ ). In ram mode, the highest thrust occurs at the lowest Mach number, highest acceleration, and highest dynamic pressure. The maximum thrust for the MAX-1B vehicle in this work was $40 \mathrm{kN}$, which corresponds to Mach 4.5, a dynamic pressure of $100 \mathrm{kPa}$, and an acceleration of $3 \mathrm{~m} / \mathrm{s}^{2}$. In ram mode, the required thrust decreases by about $5 \mathrm{kN}$ for every increase of $0.5 \mathrm{Mach}$; and for every decrease of $5 \mathrm{kPa}$ in the pressure, the required thrust decreases by about $1 \mathrm{kN}$.

Figure $18 \mathrm{~b}$ shows the instantaneous fuel consumption as a function of time for the two trajectories, and Fig. 18c shows the integrand of Eq. (14). The figure shows that the higher-altitude trajectory performs better over the intermediate Mach number range, while lower altitudes are preferred outside this range.

Therefore, it was decided to investigate what improvements could be made by no longer remaining on a constant dynamic pressure path. This creates a new trajectory optimization problem where both the acceleration and altitude may vary as a function of Mach number. The flight-path angle was constrained to be between -4 and $+4 \mathrm{deg}$, and the altitude was constrained such that the dynamic pressure remained between 50 and $100 \mathrm{kPa}$. Figure 19 shows the results for two separate cases. Trajectory $A$ is the optimum path from Mach 4.5 to Mach 7 with no additional constraints on the initial and final altitude. The

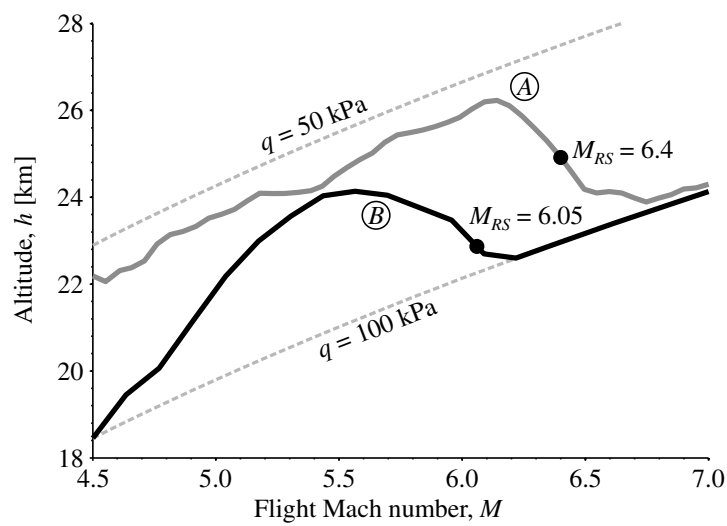

a) Altitude h: ram-scram transition is marked for both trajectories

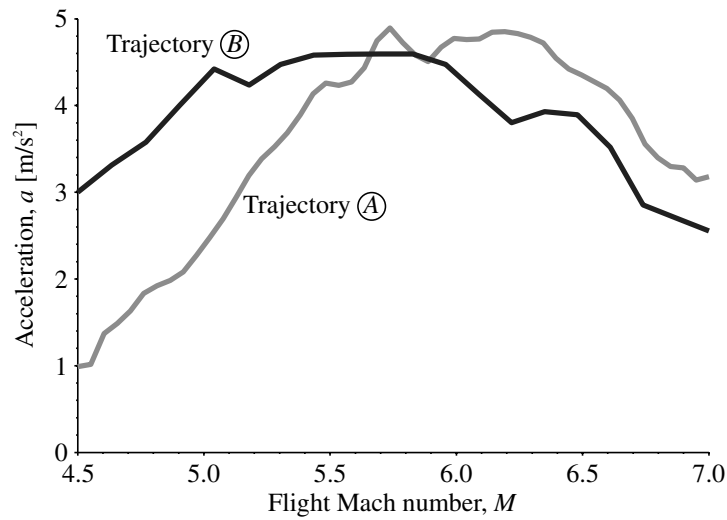

b) Acceleration $a$

Fig. 19 Comparison of two optimized trajectories without constant dynamic pressure constraint. The initial $(M=4.5)$ and final $(M=7)$ dynamic pressures are constrained to $100 \mathrm{kPa}$ for trajectory $B$. 
result can be described roughly as flying at a constant dynamic pressure of $55 \mathrm{kPa}$ until ram-scram transition and then flying near the maximum dynamic pressure after transition. The total fuel consumption for trajectory $A$ is $826 \mathrm{~kg}$.

Trajectory $B$ shows a case where both the initial and final altitudes are constrained to specific values, which correspond to a dynamic pressure of $100 \mathrm{kPa}$. The total fuel consumption is $936 \mathrm{~kg}$. The optimization produced a trajectory that initially climbs faster than the constant dynamic pressure curve, which allows the engine to remain in ram mode for a longer period. After passing through ram-to-scram transition during a descent, the vehicle then flies at the maximum dynamic pressure. Interestingly, both trajectories $A$ and $B$ contain descent phases. The descent is caused by the combination of a desire to remain in ram mode longer by flying at a higher altitude and the advantage of flying at the highest dynamic pressure allowable in scram mode. Maintaining ram mode to higher Mach numbers faces additional operational constraints including internal temperature and pressure limits (due to higher compression in ram mode) and blowout (due to higher altitudes). These constraints were not fully considered here. This shows that, for dual-mode engine operation, the optimum trajectory may not be obvious, and an accurate model is required to determine the best trajectory to fly.

\section{Conclusions}

It was found that a generic hypersonic vehicle could be trimmed along many ascent trajectories, and its performance could be computed and optimized. This has not been presented previously with a first-principles model with this level of fidelity. To do so, it was necessary to combine the MASTrim and MASIV codes that were developed by the authors. The resulting model is a significant improvement over previous efforts because it uses first-principles conservation equations to compute the inlet efficiency (including shock wave interactions), the combustion efficiency (based on finiterate chemistry and a fuel-air mixing model), and the nozzle efficiency.

It was found that trajectories with minimum total fuel consumption may be fairly complex for cases including transition from subsonic combustion (ram mode) to supersonic combustion (scram mode). Because of lower airspeeds in the combustor during subsonic combustion, ram-mode operation tends to produce more thrust for the same amount of fuel. As a result, optimized trajectories were shown to favor strategies to keep the engine in ram-mode operation as long as possible.

When operating in scram mode, maximum acceleration combined with maximum dynamic pressure was found to be a good heuristic for a true optimized trajectory in most cases. However, the maximum acceleration was not found to be associated with a fuel-air equivalence ratio of unity. In general, the acceleration is limited by the availability of oxygen. If a small portion of the fuel burns, this may result in equivalence ratios above 1.0. This excess fuel is potentially beneficial because it can be used for film cooling of the walls. Flying at a higher dynamic pressure leads to lower trim angle of attack and lower flight-path angle, which lowers the drag coefficient, and thus total fuel consumption for an ascent trajectory.

By replacing time with velocity as the variable of integration in the trajectory fuel consumption calculation, it was possible to derive an informative condition for the optimum acceleration. The result indicates that the maximum acceleration is optimal when the acceleration is not a smooth function of fuel mass flow rate and it slightly below the maximum acceleration otherwise. This was consistent with the results of directly optimizing the acceleration profile.

\section{Acknowledgments}

This research was funded by the U.S. Air Force Research Laboratory (AFRL)/Air Vehicles Directorate grant FA 8650-07-23744 for the Michigan/AFRL Collaborative Center in Control Sciences, with Michael Bolender as Technical Monitor (case number 88ABW-2013-3890).

\section{References}

[1] Chichka, D. F., Shankar, U. J., Cliff, E. M., and Kelley, H. J., "CruiseDash-Climb Analysis of an Airbreathing Missile," Journal of Guidance, Control, and Dynamics, Vol. 11, No. 4, 1988, pp. 293-299. doi: $10.2514 / 3.20310$

[2] Calise, A. J., Corban, J. E., and Flandro, G. A., “Trajectory Optimization and Guidance Law Development for National Aerospace Plane Applications," American Control Conference, American Automatic Control Council, Troy, NY, 1988, pp. 1406-1411.

[3] Corban, J. E., Calise, A. J., and Flandro, G. A., "Rapid Near-Optimal Aerospace Plane Trajectory Generation and Guidance," Journal of Guidance, Control, and Dynamics, Vol. 14, No. 6, 1991, pp. 1181-1190. doi:10.2514/3.20773

[4] Powell, R. W., Shaughnessy, J. D., Cruz, C. I., and Naftel, J. C., "Ascent Performance of an Air-Breathing Horizontal-Takeoff Launch Vehicle," Journal of Guidance, Control, and Dynamics, Vol. 14, No. 4, 1991, pp. 834-839. doi: $10.2514 / 3.20719$

[5] Olds, J. R., and Budianto, I. A., "Constant Dynamic Pressure Trajectory Simulation with POST," Aerospace Sciences Meeting and Exhibit, AIAA Paper 1998-0302, 1998.

[6] McGinnis, P. M., "Robust Hypersonic Conceptual Design Trajectory Techniques for PMDO Applications Using POST," 41st AIAA/ASME/ SAE/ASEE Joint Propulsion Conference and Exhibit, AIAA Paper 2005-4423, 2005.

[7] Lu, P., "Inverse Dynamics Approach to Trajectory Optimization for an Aerospace Plane," Journal of Guidance, Control, and Dynamics, Vol. 16, No. 4, 1993, pp. 726-732. doi: $10.2514 / 3.21073$

[8] Lu, P., "Analytical Solutions to Constrained Hypersonic Flight Trajectories," Journal of Guidance, Control, and Dynamics, Vol. 16, No. 5, 1993, pp. 956-960. doi: $10.2514 / 3.21107$

[9] Shaughnessy, J. D., Pinckney, S. Z., Mcminn, J. D., Cruz, C. I., and Kelley, M.-L., "Hypersonic Vehicle Simulation Model: Winged-Cone Configuration," NASA TM-102610, 1990.

[10] Robinson, M. J., Mee, D. J., and Paull, A., "Scramjet Lift, Thrust and Pitching-Moment Characteristics Measured in a Shock Tunnel," Journal of Propulsion and Power, Vol. 22, No. 1, 2006, pp. 85-95. doi:10.2514/1.15978

[11] Dalle, D. J., Fotia, M. L., and Driscoll, J. F., "Reduced-Order Modeling of Two-Dimensional Supersonic Flows with Applications to Scramjet Inlets," Journal of Propulsion and Power, Vol. 26, No. 3, 2010, pp. 545-555. doi: $10.2514 / 1.46521$

[12] Torrez, S. M., Driscoll, J. F., Ihme, M., and Fotia, M. L., "Reduced Order Modeling of Turbulent Reacting Flows with Application to Scramjets," Journal of Propulsion and Power, Vol. 27, No. 2, 2011, pp. 371-382. doi: $10.2514 / 1.50272$

[13] Dalle, D. J., Torrez, S. M., and Driscoll, J. F., "Rapid Analysis of Scramjet and Linear Plug Nozzles," Journal of Propulsion and Power, Vol. 28, No. 3, 2012, pp. 545-555. doi:10.2514/1.B34391

[14] Torrez, S. M., Dalle, D. J., and Driscoll, J. F., "New Method for Computing Performance of Choked Reacting Flows and Ram-to-Scram Transition," Journal of Propulsion and Power, Vol. 29, No. 2, 2013, pp. 433-445. doi:10.2514/1.B34496

[15] Bolender, M. A., and Doman, D. B., "Nonlinear Longitudinal Dynamical Model of an Air-Breathing Hypersonic Vehicle," Journal of Spacecraft and Rockets, Vol. 44, No. 2, 2007, pp. 374-387. doi: $10.2514 / 1.23370$

[16] Bowcutt, K. G., "Multidisciplinary Optimization of Airbreathing Hypersonic Vehicles," Journal of Propulsion and Power, Vol. 17, No. 6, 2001, pp. 1184-1190. doi: $10.2514 / 2.5893$

[17] Bowcutt, K., Gonda, M., Ralston, T., III, and Hollowell, S., "Performance, Economic, and Operational Drivers of Reusable Launch Vehicles," 38th AIAA/ASME/SAE/ASEE Joint Propulsion Conference and Exhibit, AIAA Paper 2002-3901, 2002.

[18] Bowcutt, K. G., Kuruvila, G., Grandine, T. A., Hogan, T. A., and Cramer, E. J., "Advancements in Multidisciplinary Design Optimization Applied to Hypersonic Vehicles to Achieve Closure," 15th AIAA Internationa Space Planes and Hypersonic Systems and Technologies Conference, AIAA Paper 2008-2591, 2008.

[19] Dissel, A. F., Kothari, A. P., and Lewis, M. J., "Investigation of TwoStage-to-Orbit Airbreathing Launch-Vehicle Configurations," Journal of Spacecraft and Rockets, Vol. 43, No. 3, 2006, pp. 568-574. doi: $10.2514 / 1.17916$ 
[20] Bradley, M., Bowcutt, K., McComb, J., Bartolotta, P., and McNeils, N., "Revolutionary Turbine Accelerator (RTA) Two-Stage-to-Orbit (TSTO) Vehicle Study," 38th AIAA/ASME/SAE/ASEE Joint Propulsion Conference and Exhibit, AIAA Paper 2002-3902, 2002.

[21] Kothari, A. P., Livingston, J. W., Tarpley, C., Raghavan, V., Bowcutt, K. G., and Smith, T. R., "Rocket Based Combined Cycle Hypersonic Vehicle Design for Orbital Access," 17th AIAA International Space Planes and Hypersonic Systems and Technologies Conference, AIAA Paper 2011-2338, 2011.

[22] Smith, T., Bowcutt, K., Selmon, J., Miranda, L., Northrop, B., Mairs, R., Unger, E., Lau, K., Silvester, T., Alesi, H., Paull, A., Paull, R., and Dolvin, D., "HIFiRE 4: A Low-Cost Aerodynamics, Stability, and Control Hypersonic Flight Experiment," 17th AIAA International Space Planes and Hypersonic Systems and Technologies Conference, AIAA Paper 2011-2275, 2011.

[23] Bolender, M. A., Staines, J. T., and Dolvin, D. J., "HIFiRE 6: An Adaptive Flight Control Experiment," 50th AIAA Aerospace Sciences Meeting, AIAA Paper 2012-0252, 2012.

[24] Oppenheimer, M. W., Skujins, T., Bolender, M. A., and Doman, D. B., "A Flexible Hypersonic Vehicle Model Developed with Piston Theory," Proceedings of the 2007 Atmospheric Flight Mechanics Conference and Exhibit, AIAA Paper 2007-6396, Aug. 2007.

[25] Bolender, M. A., and Doman, D. B., "Modeling Unsteady Heating Effects on the Structural Dynamics of a Hypersonic Vehicle," Proceedings of the 2006 Atmospheric Flight Mechanics Conference and Exhibit, AIAA Paper 2006-6646, Aug. 2006.

[26] Chavez, F. R., and Schmidt, D. K., "Analytical Aeropropulsive/ Aeroelastic Hypersonic-Vehicle Model with Dynamic Analysis," Journal of Guidance, Control, and Dynamics, Vol. 17, No. 6, 1994, pp. $1308-1319$. doi:10.2514/3.21349

[27] Starkey, R. P., "Scramjet Optimization for Maximum Off-Design Performance," 40th AIAA/ASME/SAE/ASEE Joint Propulsion Conference and Exhibit, AIAA Paper 2004-3343, 2004.

[28] Frendreis, S. G. V., and Cesnik, C. E. S., "3D Simulation of a Flexible Hypersonic Vehicle," Atmospheric Flight Mechanics Conference \& Exhibit, AIAA Paper 2010-8229, 2010.

[29] Dalle, D. J., Frendreis, S. G. V., Driscoll, J. F., and Cesnik, C. E. S., "Hypersonic Vehicle Flight Dynamics with Coupled Aerodynamics and Reduced-Order Propulsive Models," AIAA Atmospheric Flight Mechanics Conference and Exhibit, AIAA Paper 2010-7930, 2010.

[30] Carter, P. H., II, Pines, D. J., and von Eggers Rudd, L., "Approximate Performance of Periodic Hypersonic Cruise Trajectories for Global
Reach,” Journal of Aircraft, Vol. 35, No. 6, 1998, pp. 857-867. doi: $10.2514 / 2.2405$

[31] Dalle, D. J., Torrez, S. M., Driscoll, J. F., and Bolender, M. A., "Flight Envelope Calculation of a Hypersonic Vehicle Usinga First PrinciplesDerived Model," 17th AIAA International Space Planes and Hypersonic Systems and Technologies Conference, AIAA Paper 2011-2394, 2011.

[32] Torrez, S. M., Dalle, D. J., and Driscoll, J. F., "Design of Dual-Mode Engine Flowpaths for Hypersonic Vehicles Using Reduced-Order Models," 17th AIAA International Space Planes and Hypersonic Systems and Technologies Conference, AIAA Paper 2011-2380, April 2011.

[33] Torrez, S. M., Driscoll, J. F., Dalle, D. J., and Fotia, M. L., "Preliminary Design Methodology for Hypersonic Engine Flowpaths," 16th AIAA/ DLR/DGLR International Space Planes and Hypersonic Systems and Technologies Conference, AIAA Paper 2009-7289, 2009.

[34] Dalle, D. J., Torrez, S. M., and Driscoll, J. F., "Performance Analysis of Variable-Geometry Scramjet Inlets Using a Fundamental Model," 47th AIAA/ASME/SAE/ASEE Joint Propulsion Conference and Exhibit, AIAA Paper 2011-5756, 2011.

[35] Anderson, J. D., Modern Compressible Flow with Historical Perspective, McGraw-Hill, New York, 2002, pp. 133-142.

[36] Shapiro, A. H., Dynamics and Thermodynamics of Compressible Fluid Flow, Ronald Press, New York, 1953, pp. 255-260.

[37] Oppenheimer, M. W., and Doman, D. B., "A Hypersonic Vehicle Model Developed with Piston Theory," AIAA Atmospheric Flight Mechanics Conference and Exhibit, AIAA Paper 2006-6637, 2006.

[38] Vick, T. J., Muse, J. A., and Bolender, M. A., "A Hypersonic Vehicle Model Generator for MASIV," AIAA Modeling and Simulation Technologies Conference, AIAA Paper 2012-4563, 2012.

[39] Van Driest, E. R., "The Problem of Aerodynamic Heating," Aeronautical Engineering Review, Vol. 15, No. 10, 1956, pp. 26-41.

[40] Chudoba, B., "Aircraft Volume and Mass Guidelines," National Institute of Aerospace TR, Hypersonic Educational Initiative Hypersonic Vehicle System Integration Short Course, Hampton, VA, June 2008.

[41] Heiser, W. H., and Pratt, D. T., Hypersonic Airbreathing Propulsion, AIAA, Washington, D.C., 1994, pp. 342-344.

[42] Broyden, C. G., "A Class of Methods for Solving Nonlinear Simultaneous Equations," Mathematics of Computation, Vol. 19, No. 92,1965 , pp. $577-593$. doi:10.1090/S0025-5718-1965-0198670-6

[43] "U.S. Standard Atmosphere," U.S. Government Printing Office, Washington, D.C., 1976. 